Florida International University

FIU Digital Commons

6-21-2019

\title{
Inoculating Rhizobium and Arbuscular Mycorrhizal Fungi on Snap Bean Under Salinity Stress to Study Plant Growth and Glomalin Production Effects
}

Claudia Lyl Garcia

Florida International University, cgarc382@fiu.edu

Follow this and additional works at: https://digitalcommons.fiu.edu/etd

Part of the Agricultural Science Commons, Agronomy and Crop Sciences Commons, and the Environmental Microbiology and Microbial Ecology Commons

\section{Recommended Citation}

Garcia, Claudia Lyl, "Inoculating Rhizobium and Arbuscular Mycorrhizal Fungi on Snap Bean Under Salinity Stress to Study Plant Growth and Glomalin Production Effects" (2019). FIU Electronic Theses and Dissertations. 4245.

https://digitalcommons.fiu.edu/etd/4245

This work is brought to you for free and open access by the University Graduate School at FIU Digital Commons. It has been accepted for inclusion in FIU Electronic Theses and Dissertations by an authorized administrator of FIU Digital Commons. For more information, please contact dcc@fiu.edu. 


\title{
FLORIDA INTERNATIONAL UNIVERSITY
}

Miami, Florida

\section{INOCULATING RHIZOBIUM AND ARBUSCULAR MYCORRHIZAL FUNGI ON SNAP BEAN UNDER SALINITY STRESS TO STUDY PLANT GROWTH AND GLOMALIN PRODUCTION EFFECTS}

\author{
A thesis submitted in partial fulfillment of the \\ requirements for the degree of \\ MASTER OF SCIENCE \\ in \\ ENVIRONMENTAL STUDIES
}

by

Claudia Lyl Garcia 
To: Dean Michael R. Heithaus

College of Arts, Sciences and Education

This thesis, written by Claudia Lyl Garcia, and entitled Inoculating Rhizobium and Arbuscular Mycorrhizal Fungi on Snap Bean Under Salinity Stress to Study Plant Growth and Glomalin Production Effects, having been approved in respect to style and intellectual content, is referred to you for judgment.

We have read this thesis and recommend that it be approved.

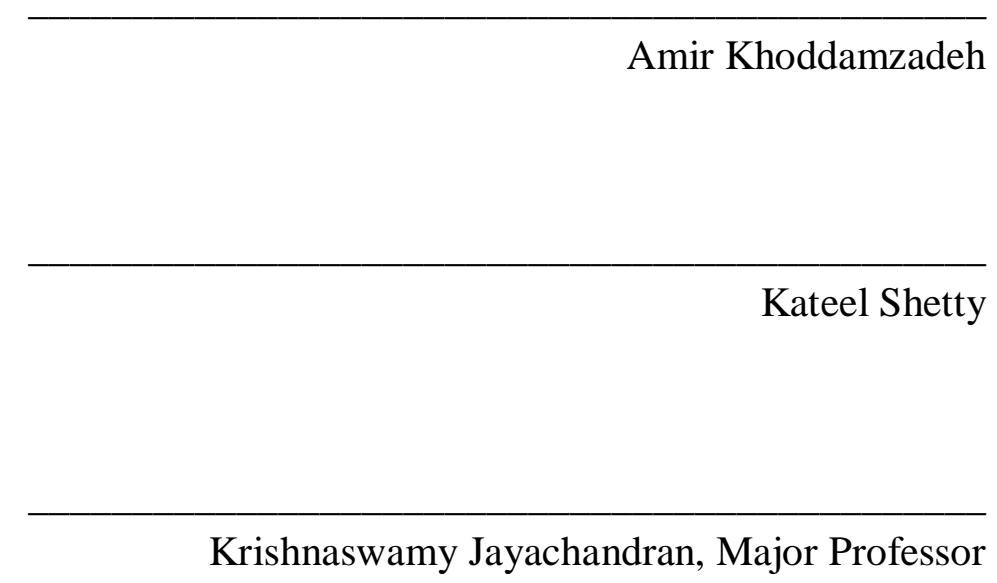

Date of Defense: June 21, 2019

The thesis of Claudia Lyl Garcia is approved.

Dean Michael R. Heithaus
College of Arts, Sciences and Education

Florida International University, 2019 


\section{ACKNOWLEDGMENTS}

I would like to express my sincerest gratitude to my committee members for their continued support and encouragement throughout this entire process: Dr. Krishnaswamy Jayachandran, my committee chair, Dr. Kateel Shetty; and Dr. Amir Khoddamzadeh. The learning opportunities presented to me by my committee were both profound and valuable. I am very thankful to be under the wonderful mentorship of Dr. Saoli Chanda, who guided me patiently through various laboratory protocols and statistical analysis. Words are not enough to express how much I appreciate the time and effort she put into mentoring me. I would like to extend that gratitude to: Dr. Sanku Dattamudi, who also aided me greatly the last legs of my project; Ariel Freidenreich for her greatly appreciated guidance in dry biomass and AMF root colonization training; and to Mary Tiedeman for soil moisture content and aggregate stability training. I want to thank my fellow graduate students Daphne Sugino and Jordan Prats for always supporting me and for their help in sampling and termination assistance in my project as well as Nicholas Charles for his editing and supportive feedback. I would also like to thank Eric Betancourt for his valuable advice and guidance throughout my years in the Agroecology program. Thanks to my fellow graduate students who have made this experience unique and priceless and to the undergraduate students Ana Malagon, and Kevin Lewin for their help in data collection. My most profound thanks to my brother, Adrian Garcia for always supporting and aiding in my project. Finally, this was all possible thanks to the funding of the United States Department of Agriculture NIFA Hispanic-Serving Institutions Higher Education Grants Program (2016-38422-25542). 


\begin{abstract}
OF THE THESIS
INOCULATING RHIZOBIUM AND ARBUSCULAR MYCORRHIZAL FUNGI ON SNAP BEAN UNDER SALINITY STRESS TO STUDY PLANT GROWTH AND GLOMALIN PRODUCTION EFFECTS
\end{abstract}

\author{
by \\ Claudia Lyl Garcia \\ Florida International University, 2019 \\ Miami, Florida \\ Professor Krishnaswamay Jayachandran, Major Professor
}

Groundwater salinization from saltwater intrusion threatens Southeastern Florida's commercially important snap bean (Phaseolus vulgaris) production because of the crop's low salt-tolerance threshold. The present study was carried out to determine if coinoculating salt-stressed snap beans with beneficial microbial symbionts (i.e., Rhizobium and arbuscular mycorrhizal fungi) can mitigate growth reductions. Additionally, the study also assessed whether co-inoculation had an effect on the production of glomalin, a protein secreted by arbuscular mycorrhizal fungi that improves soil aggregation. Snap beans were inoculated (-AMF/-Rhizobium, $+\mathrm{AMF} /-$ Rhizobium, $+\mathrm{AMF} /+$ Rhizobium) and irrigated with varying salinity levels $\left(0.6,1.0,2.0 \mathrm{dS} \mathrm{m}^{-1}\right)$. Results indicate that coinoculation had a synergetic effect on salt-stressed snap beans to a certain degree. Coinoculation alleviated chlorosis effects on salt-stressed snap beans by increasing leaf chlorophyll concentration. Additionally, co-inoculation had a minor inhibitory effect on 
glomalin production regardless of salinity treatment. This study expands knowledge on sustainable practices aimed in improving salt-thresholds of salt-sensitive crops. 


\section{TABLE OF CONTENTS}

\section{Contents}

SECTION

PAGE

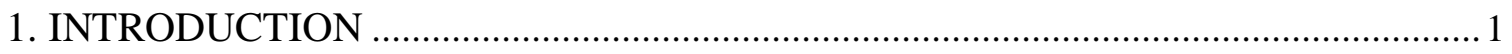

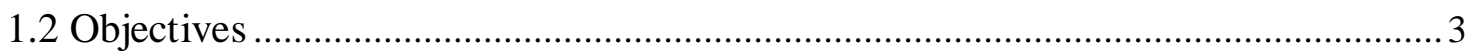

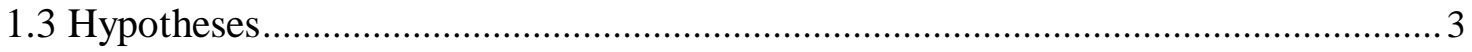

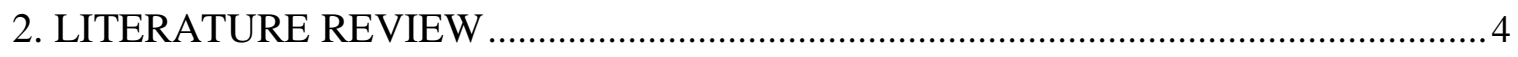

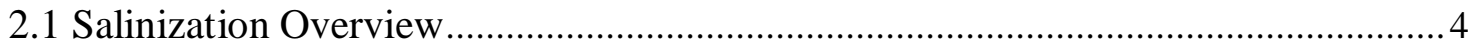

2.2 Saltwater Intrusion, Climate Change, and Freshwater Aquifers ............................. 6

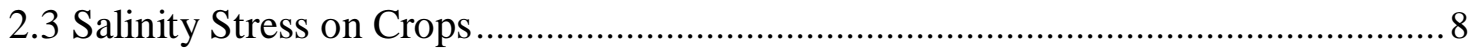

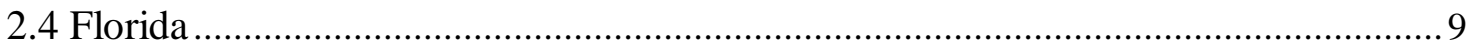

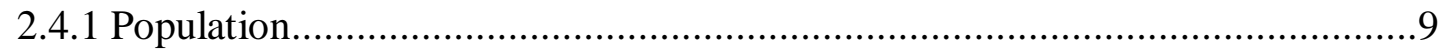

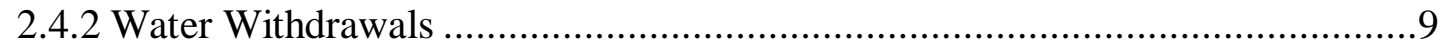

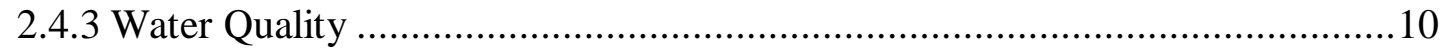

2.4.4 Agriculture Production and Snap Beans ............................................... 14

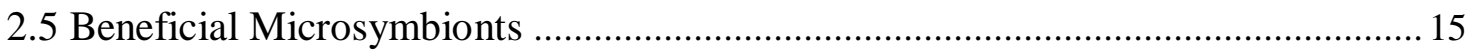

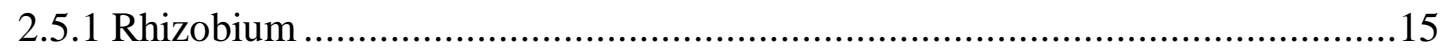

2.5.2 Arbuscular Mycorrhizal Fungi .............................................................. 16

2.5.3 Tripartite Symbiosis........................................................................ 18

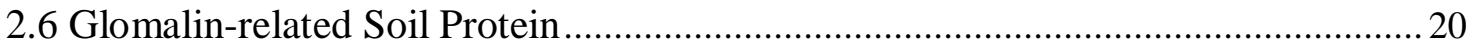

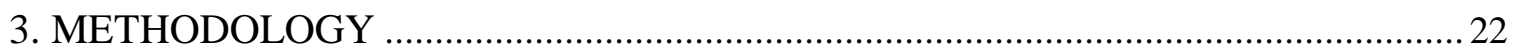

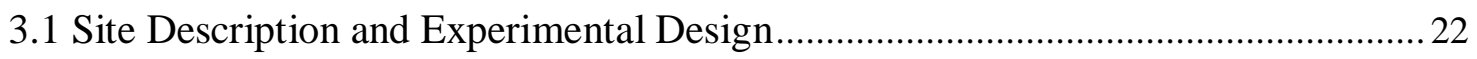

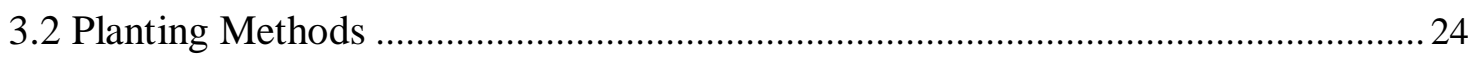

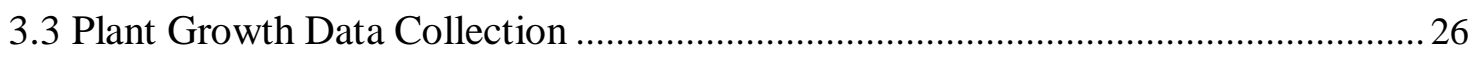

3.3.1 Plant Height, Leaf Chlorophyll Concentration, and Bean Yield .....................26

3.3.2 Shoot and Root Dry Biomass ...............................................................2

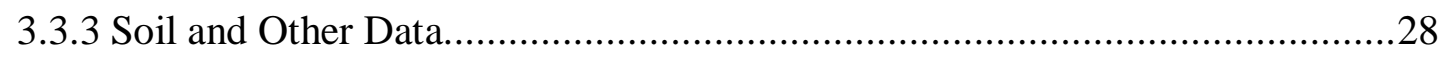

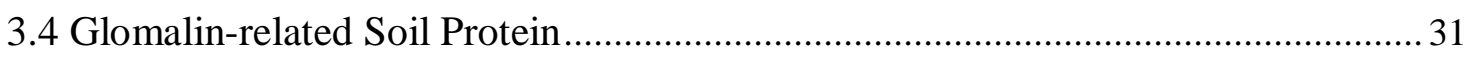

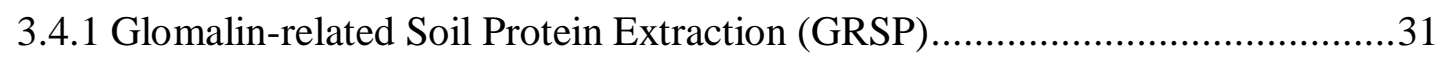

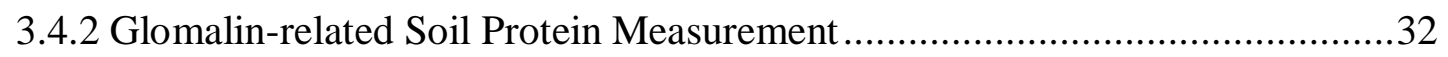




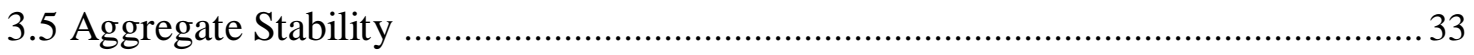

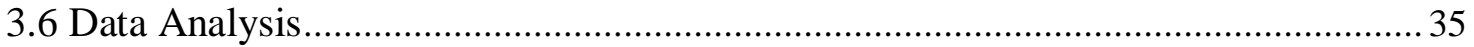

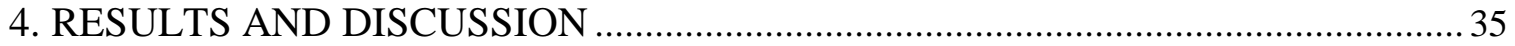

4.1 ANOVA and Table for Total Bean Yield, Root and Shoot Dry Weight and

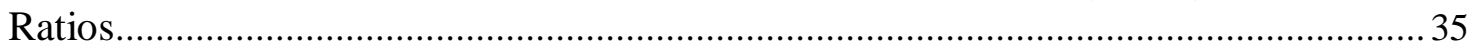

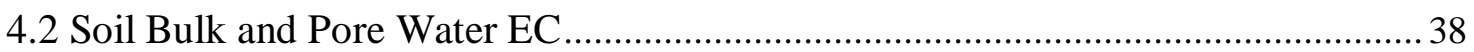

4.3 Pore Water EC vs Soil Bulk EC Regression Line.............................................. 42

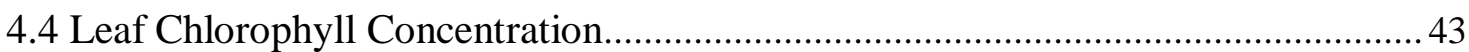

4.5 Root arbuscular mycorrhizal percent infection, soil moisture, and soil $\mathrm{pH}$............ 45

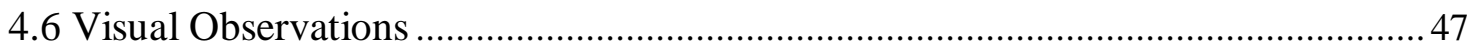

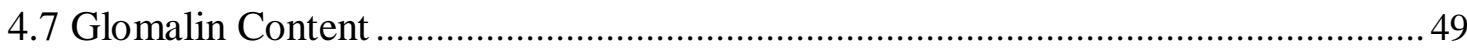

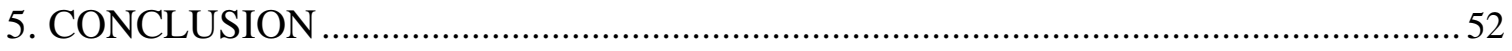

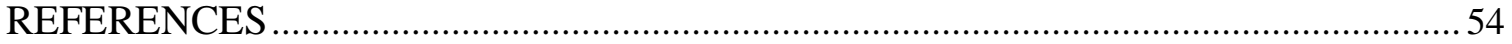




\section{LIST OF TABLES}

TABLE

PAGE

Table 1 Quality Classification of water quality and salt-affected soils showcasing the general salinity threshold (EC) for some of Florida's highest valued vegetable crops......6

Table 2 Effect of salinity level and inoculation type on snap bean characteristics ...........36

Table 3 Effect of salinity level and inoculation type on soil and root properties. ...........46 


\section{LIST OF FIGURES}

FIGURE

PAGE

Figure 1 Water Level and Salinity Analysis map showcasing; (a) the approximate inland extent of saltwater intrusion southeast of Miami, Florida and (b) a closer look at Homestead, Florida.

Figure 2 A 3 x 3 factorial randomized block design showcasing the salinity concentration and inoculant mixture combinations in a potted experiment..

Figure 3 The nine treatments of the potted experiment at Florida International University.

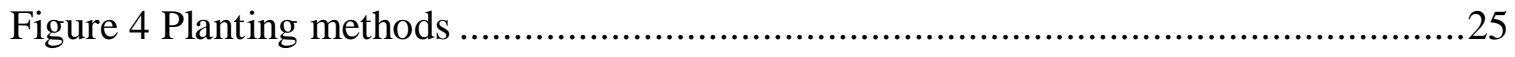

Figure 5 Plant growth data collection .............................................................27

Figure 6 Snap bean roots stained with Trypan blue: a) non-infected root and b) root colonized by arbuscular mycorrhizal fungi........................................................ 30

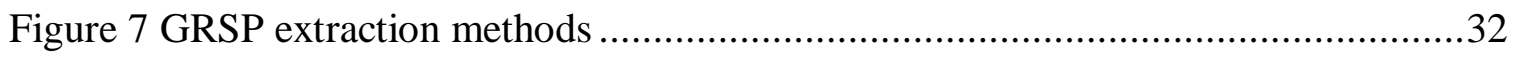

Figure 8 General blank, standard, and GRSP sample arrangement for microplate reader to determine GRSP concentration after using the Bradford Assay .......................33

Figure 9 Scatter line graph depicting a) how the pore water EC in the soil changes over time and b) how soil bulk EC changes over time

Figure 10 Linear regression analysis depicting soil bulk vs pore water electrical conductivity (EC) for all nine treatments

Figure 11 Graph depicting mean Soil Plant Analytical Development (SPAD) values for nine treatments (inoculation type x salinity level) on Caprice snap beans during weeks $2,4,6$, and 8 of the growth period..

Figure 12 Visual representation of varying salinity effects on snap bean leaves prior to termination

Figure 13 Graph depicting mean a) Easily Extractable Glomalin-related Soil Protein (EEG) and b) Total Glomalin-related Soil Protein (TG) per $\mathrm{mg} \mathrm{g}^{-1}$ of dry soil for all nine treatments (inoculation type x salinity level) on Caprice snap beans. 


\section{INTRODUCTION}

Salinization is a serious environmental threat that negatively impacts agricultural productivity on a global scale, accounting for 1.5 million ha of agricultural land loss a year (FAO, 2015). The salinization of soils and groundwater resources is considered to be a growing problem that limits crop growth and yield, lowering water availability, and causing plant toxicity (Evelin et al., 2019; Numan et al., 2018; Manchanda \& Garg, 2008). Salinization has led to substantial economic losses within the agriculture sector (FAO, 2015) as well as raised major concern towards ensuring global food security. Soil and groundwater salinity have resulted in substantial yield reductions of agricultural crops and thus invites the scientific community to find cost-effective ways to grow salt tolerant commercial crops for better sustainability management and planning.

Numerous studies have been done in an attempt to identify sustainable management practices that improve crop growth in saline conditions (Evelin et al. 2019; Ren et al., 2016; Talaat, 2015; Bothe, 2012). One commonly used method involves inoculating salt-stressed crops with beneficial microsymbionts (microscopic organisms that can form symbiotic relationships) that promote plant growth. Arbuscular mycorrhizal fungi (AMF) and Rhizobium bacteria have shown to provide a low-cost and natural means of improving nutrient acquisition in various stressed conditions such as drought, heat-stress, and poor nutrient soils (Hack et al., 2019; Wang et al., 2011; Al-garni, 2006; Diouf et al., 2005). In several cases, these microsymbionts have been shown to individually mitigate stress effects on crops to a certain extent, improving overall health through increased nutrient uptake, water availability, and biological nitrogen fixation 
(Evelin et al., 2019; Latef et al., 2016; Ren et al., 2016; Bothe, 2012; Azcón \& El-Atrash, 1997; Ruiz Lozano et al., 1995). However, many of these studies focused on singular inoculation and thus leave certain gaps of knowledge within the literature for coinoculation practices in saline conditions.

Snap bean (Phaseolus vulgaris) is a leguminous plant and one of Florida's most commercially important vegetable crops, planted across more than 28,200 acres with a commercial value of $\$ 105.6$ million in 2016 (Vegetable Production Handbook of Florida, 2017). When grown in saline soils or irrigated with salt-rich water, snap bean growth is drastically affected as a result of its low salt-tolerance threshold $\left(1.0 \mathrm{dS} \mathrm{m}^{-1}\right)$ (Table 1). The majority of snap bean production takes place in Palm Beach and Miami-Dade County (USDA Census of Agriculture, 2017), both of which are significantly populated and have their freshwater supply drawn primarily by the highly permeable Biscayne aquifer (Marella, 2012). Groundwater salinization in coastal cities where water is supplied by permeable freshwater aquifers has the potential to decrease the quality of irrigation sources (Zhou et al., 2017; Kaleris \& Ziogas, 2012; Barlow \& Reichard, 2010). The origin of groundwater salinization is mainly attributed to saltwater intrusion, which can be influenced by a variety of factors such as sea-level rise, climate change, and groundwater well pumping and are the leading causes of groundwater contamination (Kaleris \& Ziogas, 2012). Florida's population is expected to rise in the future which may increase water consumption (Bureau of Economic and Business Research, 2019). As a result, risks of saltwater intrusion into groundwater pumping wells increases its susceptibility to salinization. This in turn threatens the future agricultural production of crops, specifically those of the salt-sensitive variety. 
Therefore, this study has been planned to evaluate the effects of salt on snap bean productions inoculated with two plant growth promoting microbial symbionts, a) Rhizobium and b) arbuscular mycorrhizal fungi (AMF). As a secondary focus, I will also evaluate how the dual inoculation of Rhizobium and AMF impacts glomalin, a protein secreted by AMF with possible plant promoting properties (Wang et al., 2015). Specific objectives are:

\subsection{Objectives}

1. To determine whether dual inoculating salt-stressed snap beans with Rhizobium and arbuscular mycorrhizal fungi can mitigate reductions to the crop's growth and yield.

2. To assess the effect of dual inoculation on glomalin-related soil protein production.

3. To evaluate the impact of salinity stress and dual inoculation on glomalin-related soil protein production.

\subsection{Hypotheses}

1. Inoculating salt-stressed snap beans with both Rhizobium and arbuscular mycorrhizal fungi will have a synergetic effect on overall plant growth and yield due to the plant promoting properties of the microsymbionts.

2. Glomalin- related soil protein production by arbuscular mycorrhizal fungi will increase if snap bean is dual inoculated. 
3. Glomalin--related soil protein production by arbuscular mycorrhizal fungi will increase while under salinity stress if snap bean is dual inoculated.

\section{LITERATURE REVIEW}

\subsection{Salinization Overview}

Salinization is the accumulation of water-soluble salts such as sodium chloride $(\mathrm{NaCl})$ at high concentrations within the soil or groundwater (Rengasamy, 2002). Salinization can be categorized in two ways; (a) primary salinization which occurs through natural means (e.g. weathering of parent material containing high concentrations of soluble salts, high evaporation/low precipitation rates, etc.), and (b) secondary salinization caused by human-induced processes (e.g. poor soil drainage, irrigating with salt-rich water, saltwater intrusion into coastal groundwater aquifers caused by sea level rise, and other harmful agricultural management practices) (Status of the Soil World's Resources, 2015; Rengasamy, 2002). The increasing salinity of the world's soil and freshwater resources is considered to be a serious issue worldwide, with major concern towards food security, land degradation, and agricultural production and economic loss.

Salt-affected soils are widespread and are estimated to be distributed across 1 billion ha worldwide, with more than 100 countries currently affected. Of these affected countries, agricultural land loss caused by rising salinity problems is estimated to be as high as 1.5 million ha per year (Status of the Soil World's Resources, 2015). The majority of salt-affected soils are located within arid and semi-arid regions, where high evaporation and low precipitation rates are predominant. As water evaporates from the soil, water soluble salts remain and accumulate within the rhizosphere because rainfall 
amounts are insufficient in leaching salts from the soil profile (Status of the Soil World's Resources, 2015; FAO, 1992).

Secondary salinization, while not as accountable for salt-affected areas as primary salinization, is still responsible for approximately 76 million ha of salt-affected soils (Status of the Soil World's Resources, 2015). Farmlands that are irrigated with low quality water face the risk of increased salinization because of the addition of salts within the soil surface. Additionally, sourcing irrigation water from groundwater supply wells can affect coastal aquifers if the recharge to the aquifer is insufficient, increasing the risk of saltwater intrusion and groundwater salinization to these vulnerable systems (Evelin et al., 2019; Zhou et al., 2017; Barlow \& Reichard, 2010).

Salinity within the soil or groundwater is usually measured by determining its electrical conductivity (EC), meaning how well an electrical current is transmitted through the medium. In terms of classification for salt-affected soils, saline soils are considered to have an EC greater than $4 \mathrm{dS} \mathrm{m}^{-1}$ (Evelin, Kapoor, \& Giri, 2009). As for water quality classifications, fresh water EC levels are generally less than $0.6 \mathrm{dS} \mathrm{m}^{-1}$, slightly brackish ranges from 0.6 to $1.5 \mathrm{dS} \mathrm{m}^{-1}$, brackish from 1.5 to $3.0 \mathrm{dS} \mathrm{m}^{-1}$, moderately saline from 3.0 to $8.0 \mathrm{dS} \mathrm{m}^{-1}$, and finally saline water from 8.0 to $15.0 \mathrm{dS} \mathrm{m}^{-1}$ (Pitman \& Läuchli, 2002). 
Table 1 Quality Classification of water quality and salt-affected soils showcasing the general salinity threshold (EC) for some of Florida's highest valued vegetable crops

\begin{tabular}{|c|c|c|c|c|c|c|}
\hline $\begin{array}{c}\text { Quality } \\
\text { Classification }\end{array}$ & $\begin{array}{c}E C \\
\left(d_{S} ~ m^{-1}\right)\end{array}$ & Crop & $\begin{array}{c}\text { Salinity } \\
\text { Tolerance }\end{array}$ & $\begin{array}{c}\text { Threshold } \\
\text { EC } \\
\left(\mathbf{d S} \mathbf{~ m}^{-1}\right) \\
\end{array}$ & $\begin{array}{l}\text { U.S. Rank } \\
\text { Production }\end{array}$ & $\begin{array}{c}\text { Value } \\
\text { (million } \\
\text { US\$) }\end{array}$ \\
\hline \multicolumn{7}{|l|}{ Water Salinity } \\
\hline Fresh & $<0.6$ & & & & & \\
\hline Slightly & $0.6-1.5$ & Tomato & MS & 0.9 & 1 & 382.2 \\
\hline \multirow[t]{4}{*}{ Brackish } & & Snap bean & $\mathrm{S}$ & 1.0 & 1 & 105.6 \\
\hline & & Cabbage & MS & 1.0 & 3 & 49.4 \\
\hline & & Cucumber & MS & 1.1 & 1 & 66.0 \\
\hline & & Strawberry & S & 1.5 & 2 & 449.7 \\
\hline \multirow{3}{*}{ Brackish } & $1.5-3.0$ & Bell pepper & MS & 1.7 & 2 & 209.7 \\
\hline & & Potato & MS & 2.0 & 11 & 117.0 \\
\hline & & Sweet corn & MS & 2.0 & 2 & 160.0 \\
\hline $\begin{array}{l}\text { Moderately } \\
\text { Saline }\end{array}$ & $3.0-8.0$ & & & & & \\
\hline \multicolumn{7}{|l|}{ Soil Salinity } \\
\hline $\begin{array}{l}\text { (Nearly) } \\
\text { Non-saline }\end{array}$ & $<0.75$ & & & & & \\
\hline \multirow[t]{6}{*}{ Low Salinity } & $0.75-2.0$ & Tomato & MS & 0.9 & 1 & 382.2 \\
\hline & & Snap bean & $\mathrm{S}$ & 1.0 & 1 & 105.6 \\
\hline & & Cabbage & MS & 1.0 & 3 & 49.4 \\
\hline & & Cucumber & MS & 1.1 & 1 & 66.0 \\
\hline & & Strawberry & $\mathrm{S}$ & 1.5 & 2 & 449.7 \\
\hline & & Bell pepper & MS & 1.7 & 2 & 209.7 \\
\hline Moderate & $2.0-4.0$ & Potato & MS & 2.0 & 11 & 117.0 \\
\hline Salinity & & Sweet corn & MS & 2.0 & 2 & 160.0 \\
\hline Saline & $4.0-8.0$ & & & & & \\
\hline
\end{tabular}

Table notes: Known crop EC thresholds are shown and categorized by their relative tolerance; sensitive (S), moderately sensitive (MS), moderately tolerant (MT), and tolerant (T). Table adapted from the following sources (Vegetable Production Handbook of Florida, 2019; Pitman and Läuchli, 2002; FAO, 1992).

\subsection{Saltwater Intrusion, Climate Change, and Freshwater Aquifers}

For coastal freshwater aquifers, saltwater intrusion can greatly impact irrigation water salinity. Saltwater intrusion is the movement of saline water into freshwater 
aquifers, which can lead to the contamination of the population's freshwater drinking resources as well an overall increase in groundwater salinity (Ferguson \& Gleeson, 2012). There are two factors that can be attributed as the major cause for coastal aquifers becoming salinized. The first is the rise in sea level which is adversely linked to climate change. As ice sheets and glaciers continue to melt as a consequence of the increase of global temperature, sea levels are estimated to increase in volume. Sea levels can also rise because of oceans and seas expanding from increasing temperatures (Werner \& Simmons, 2009; Sherif \& Singh, 1999). The second factor is brought upon by more human-induced means, which involves the pumping and extraction of groundwater from wells for human population demands such as agricultural and municipal needs.

Despite the potential detrimental effects sea-level rise could have on saltwater intrusion (and therefore freshwater aquifers), the majority of ongoing research has focused mainly on site-specific studies. However, a study by Werner and Simmons (2009) assessing the relationship between seawater and freshwater and how sea-level rise would impact unconfined coastal aquifers through saltwater intrusion resulted in two major conclusions. First, flux-controlled systems (i.e., groundwater discharge into seas continues in order to control the seawater/freshwater interface despite sea-level fluctuations) seem to be less affected by salt-water intrusion and sea-level rise. Secondly, head-controlled systems (i.e., groundwater discharge into the sea remains the same despite increasing sea levels) are much more susceptible to saltwater intrusion brought on by sea level rise. 


\subsection{Salinity Stress on Crops}

Plants undergoing salinity stress face a broad range of molecular, biochemical, and physiological changes (Numan et al., 2018; Manchanda \& Garg, 2008). High salt concentrations within the soil or irrigation water can reduce plant growth rate and yield (Gopalakrishnan et al., 2015). These reductions are caused by the plant undergoing stress in two major ways. First, the buildup of salts within the root zone lowers water availability and causes the plant to go through a physiological drought also known as osmotic stress. The water availability in saline soils is reduced as a result of salts within the rhizosphere that increase the difficulty for roots to take up water (Munns \& Tester, 2008; Press, 2005) even if soil moisture content within the soil is sufficient for development.

The second type of stress plants experience is plant toxicity. High concentrations of salt within the soil signify an increase of ions within plant tissues which can greatly impair a multitude of vital plant functions necessary for growth (Numan et al., 2018). Photosynthesis is a major plant function that is severely affected by salinity stress, often leading to reductions in leaf expansion, area, and duration (Manchanda \& Garg, 2008). Other affected functions include protein synthesis, and energy and lipid metabolism (Press, 2005). These impaired functions can limit the plant's development caused by the negative effects on the seed germination and vigor, overall plant's growth, reproduction, and yield (Evelin et al., 2019; Munns \& Tester, 2008). 


\subsection{Florida}

\subsubsection{Population}

The current global population of 7.4 billion is expected to reach 9.6 billion by the year 2050 and 10.9 billion by the next century. The projected populations for the United States in 2050 and 2100 are 401 and 462 million respectively, which is a substantial increase from 2013's population of 320 million (Food and Agriculture Organization [FAO], 2015). The University of Florida's Bureau of Economic and Business Research (2019) projects Florida's population of 20.7 million (2018) to reach as high as 30.1 million in 2040. The considerable growth to Florida's population could signify future increase to ground and surface water withdrawals in order to meet municipal and agricultural demands. A rise in population may pose future problems, as intensified groundwater withdrawals could raise aquifer vulnerability to salinization caused by saltwater intrusion and sea-level rise.

\subsubsection{Water Withdrawals}

The state of Florida withdrew more than 14,200 million gallons of water per day (Mgal/d) in 2012 from surface and groundwater sources (Marella, 2012). Out of that staggering amount, saline water was estimated to account for more than $7,800 \mathrm{Mgal} / \mathrm{d}$ (55\%) while freshwater withdrawals accounted for more than 6,300 Mgal/d (45\%). In terms of freshwater withdrawal, $65 \%$ was taken from groundwater sources while surface waters accounted for the rest. Nearly all saline water withdrawals originated from surface water sources $(99.9 \%)$, with groundwater resources accounting for less than $1.0 \%$. Additionally, fresh groundwater resources provided drinking water for 17.699 million Florida residents, which accounts for $93 \%$ of the state's population. As for agricultural 
water uses, 39\% of its withdrawals was self-supplied (34\% groundwater sources) along with $49 \%$ from groundwater public supply sources.

Although saline water from groundwater withdrawals accounted for less than $1 \%$ of total freshwater withdrawal in 2012 (Marella, 2012), potential risk of salinization to the state's groundwater resources still exist because of certain factors. These factors include the intense pumping of freshwater from supply wells for municipal and agriculture purposes, the gradual increase of sea level rise of up to $2.0 \mathrm{~m}$ by 2100 (Saha et al., 2011), and south Florida's long history (1903 to 1980s) of building extensive canal systems to drain the Everglades (Barlow and Reichard, 2010).

\subsubsection{Water Quality}

Southeastern Florida is underlain by shallow aquifers as well as the Biscayne aquifer, a highly permeable low-lying coastal aquifer where groundwater withdrawal for municipal purposes is common. The three main counties of southeastern Florida (Broward, West Palm Beach, and Miami-Dade) make up a staggering population count with numbers reaching as high as 5.5 million. Notably, these counties were attributed with substantial groundwater freshwater withdrawals (i.e., over $200 \mathrm{Mgal} / \mathrm{d}$ ); MiamiDade (429.37 Mgal/d), Palm Beach (247.78 Mgal/d), and Broward (246.30 Mgal/d) (Marella, 2012). These three counties are located southeast of the peninsula and have shallow aquifers as well as the Biscayne aquifer, which is predominantly composed of limestone and is considered to be highly permeable. Florida's increasing population, as well as a plethora of other variables (i.e., thin unsaturated zone, highly susceptible to damaging floods, high rates of evapotranspiration, and strongly controlled head waters 
through the use of overlaying canal systems) make the Biscayne and other nearby shallow aquifers highly susceptible to saltwater intrusion brought on by sea-level rise (Langevin \& Zygnerski, 2013). These saltwater intrusion effects are also expected to be higher in intensity than other coastal areas facing similar issues.

A previous report by Steinkampf (1982) on Florida production areas showcased the effects of saltwater intrusion on irrigation water quality. The study assessed production areas known to be affected by saltwater intrusion and focused on nearby irrigation wells that farmers were using. The wells were analyzed and showed that $90 \%$ of the wells were being affected. Out of those that were affected, the average salinity levels ranged from 1.0 to $4.0 \mathrm{dS} \mathrm{m}^{-1}$. These results are concerning, as several of the crops grown in Florida are salt sensitive and would see reductions in yield if irrigated with these wells.

Recent reports have also shown worrying implications for South Florida's water quality. Figure 1 depicts a Water Level and Salinity Analysis map by the United States Geological Survey (USGS) focusing on Homestead, Florida. The map within the figure showcases the approximated inland extent, or estimates, of saltwater intrusion for multiple years (i.e., 2011 and 2016). Between the five-year span from 2011 to 2016, there is a noticeable inland movement of saltwater intrusion into the Homestead area - a vital location for South Florida's agriculture (USDA Census of Agriculture, 2017). Areas that have been affected by saltwater intrusion show high salt concentrations and are classified as saline, while water samples taken further inland in areas not affected are still considered fresh due to lower salt concentrations. 
Additionally, the map also depicts that in this five-year period, there was a trend of water levels rising across the lines where saltwater intrusion was occurring. While other locations in north and south of the Homestead area were not as significantly affected, the map's trend of rising water levels and inland movement of saline water into the Florida Biscayne aquifer poses a very real and impending threat to one of South Florida's most important agricultural production areas and, subsequently, its future economical production. 


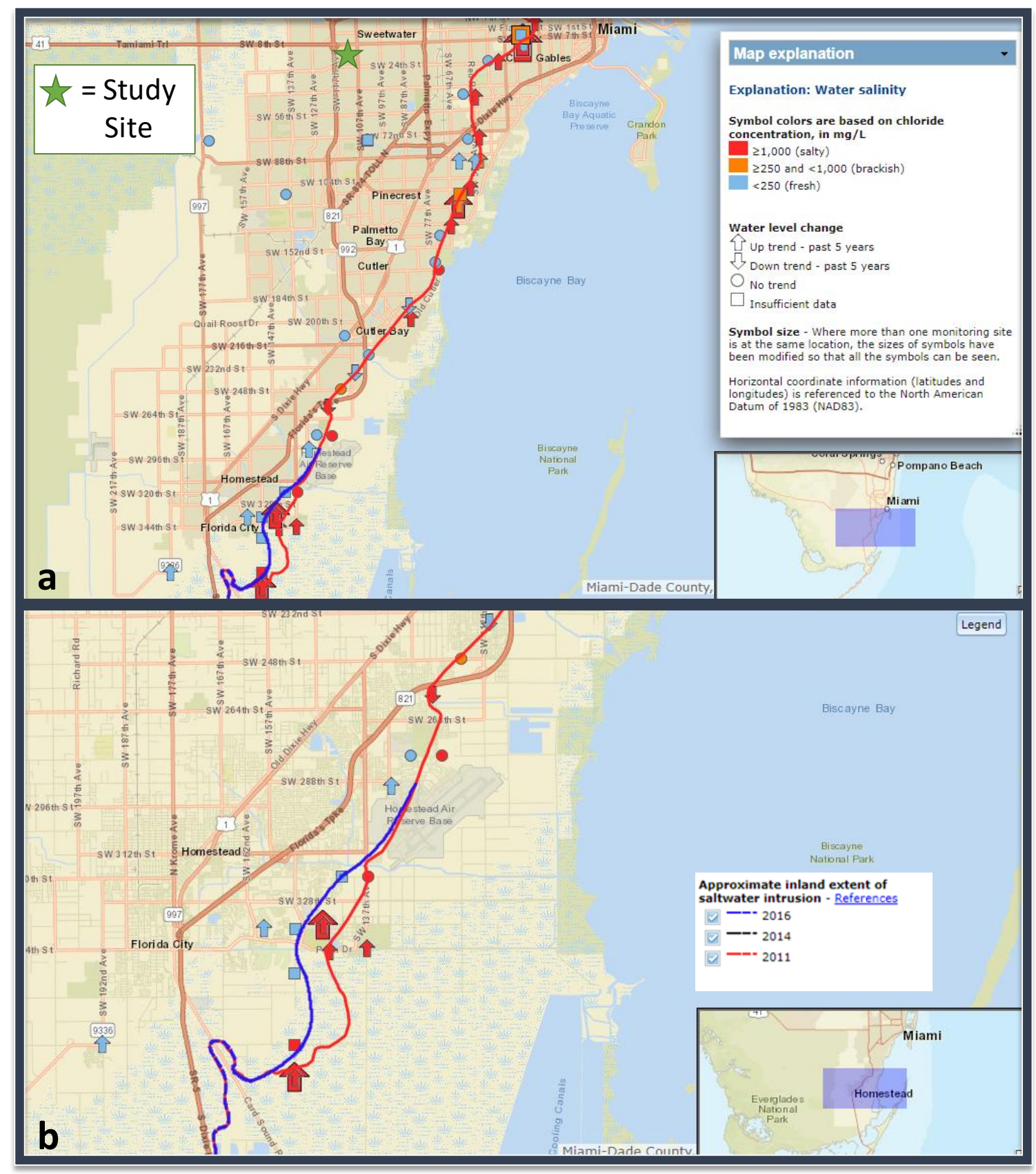

Figure 1 Water Level and Salinity Analysis map showcasing; (a) the approximate inland extent of saltwater intrusion southeast of Miami, Florida and (b) a closer look at Homestead, Florida where saltwater intrusion is more prevalent. The red dotted lines signify the estimated inland extent in 2011 while the blue indicates estimates for 2016. Upward and downward arrows indicate increasing/decreasing trends in salinity with red signifying higher salt concentrations in the aquifer. The site symbol indicates where this study took place.

(Source: https://fl.water.usgs.gov/mapper/). 


\subsubsection{Agriculture Production and Snap Beans}

Snap bean (Phaseolus vulgaris) is a leguminous crop belonging to the Fabaceae family that is greatly valued worldwide (26.8 million metric tons produced in 2016) for its high protein, dietary fibers, carbohydrates, and vitamin content (Assefa et al., 2019; Peoples et al., 2009). Florida's vegetable production is an immense industry both in agricultural land size (251,011 acres) and production value (> \$1.34 billion), ranking second overall within the United States in 2016. Snap bean production holds a commercial importance in Florida, as it is ranked $1^{\text {st }}$ within the United States and is planted across 30,000 acres with a production value of \$105.6 million in 2016 (Smith et al., 2019; Vegetable Production Handbook of Florida, 2017). Additionally, 51\% (14,222 acres) of Florida's snap bean production took place in Palm Beach $(6,667$ acres) and Miami-Dade County (7,555 acres), two heavily populated counties located within South Florida sitting atop the Biscayne aquifer (USDA Census of Agriculture, 2017).

A majority of these crops, such as snap beans and strawberries, are known for having low salinity tolerance thresholds ( When grown in soils with high salinity, the development of these salt-sensitive crops is affected, and their growth is drastically restricted along with their yield (Pitman \& Läuchli, 2002; Scholberg \& Locascio, 1999). As a result, various relevant studies focus on identifying sustainable and cost-effective ways in improving tolerance thresholds to lessen future negative impacts (Evelin et al., 2019). 


\subsection{Beneficial Microsymbionts}

\subsubsection{Rhizobium}

Rhizobium are host-specific bacteria that inhabit the roots of leguminous plants and biologically fix nitrogen. They form a symbiotic relationship with the host plant and form nodules within the roots, where atmospheric nitrogen $\left(\mathrm{N}_{2}\right)$ is converted into ammonia $\left(\mathrm{NH}_{3}\right)$, a form of nitrogen that is readily available for plant uptake (Kala, Christy, \& Bai, 2011; Aroca \& Ruiz-Lozano, 2009). Inoculating legumes with Rhizobia either directly (soil inoculation) or indirectly (seed inoculation) provides certain benefits (Deaker et al., 2004), such as an increase to biological nitrogen fixation as well as nodulation within the plant's roots (Kala et al., 2011). Some rhizobia species (Rhizobium leguminosarum, and Bradyrhizobium japonicum) have been found to be tolerant to osmotic stress, while soil salinity has shown to inhibit the legume-rhizobia symbiosis for certain salt-sensitive species ( $R$. leguminosarum), reducing nodulation and thereby lowering nitrogen content and plant productivity (Atieno \& Lesueur, 2018). However, it is generally understood that rhizobia tend to be more salt-tolerant than their host plant (Soussi et al., 2001).

Previous literature has studied the inoculation of leguminous plants with Rhizobium to assess impacts to crop growth (Franzini et al., 2019; Ashrafi et al., 2014). Inoculation has resulted in varying degrees of nodulation success and biological nitrogen fixation efficiency (Aroca \& Ruiz-Lozano, 2009). In some cases, Rhizobium has been shown to increase nodulation within leguminous crops. As reported by Gloser et al. (2007), plants grown in conditions with reduced nitrogen availability have lower root hydraulic conductivity performance than those with sufficient available nitrogen. It was 
reasoned that because of this increase in root hydraulic conductivity performance, nodulated plants (which tend to have higher nitrogen content) should perform better than non-nodulated plants in drought-like conditions (Aroca and Ruiz-Lozano, 2009).

Recently, Franzini et al. (2019) demonstrated how rhizobial symbiosis could have an influence on the host plant's root hydraulic properties in saline and non-saline conditions. In the study, snap beans grown in non-stressed and salt-stressed conditions were inoculated with $R$. leguminosarum for a total of four treatments; no inoculation/nonstressed, no inoculation/salt-stressed, inoculated/non-stressed, and inoculated/saltstressed. While no significant effects to plant growth were seen, inoculated beans presented enhanced root osmotic water flow as well as improved leaf water status in both salt-stressed and non-stressed conditions.

\subsubsection{Arbuscular Mycorrhizal Fungi}

Arbuscular mycorrhizal fungi (AMF) are ubiquitous in nature and form mutualistic interactions with more than $80 \%$ of terrestrial plants (Evelin et al., 2009; Smith \& Read, 2008). The beneficial union between fungi and plant occurs mainly in conditions where phosphorus (P) concentrations are low within the soil (Hodge, 2000). When this condition is met, AMF colonize the plant's root system and forms fungal structures known as arbuscules (considered to be the phosphorus exchange site between fungi and host). Thin root like hairs known as hyphae are also formed, which enhances the efficiency of the plant's root system by improving nutrient uptake in poor quality soils with a specific focus on phosphorus (P) acquisition. Hyphae also enhance the plant's 
root system by improving water uptake, nitrogen content, and other micronutrients (RuizLozano, 2012; Hodge, 2000; Smith \& Read, 1997).

Arbuscular mycorrhizal fungi's potential in mitigating plant stress and promoting growth under a wide range of conditions has been well documented (Evelin et al., 2019; Jeffries et al., 2003; Smith \& Read, 1997). It was determined by Wang et al. (2011) that inoculating snap beans with AMF under elevated tropospheric ozone $\left(\mathrm{O}_{3}\right)$ conditions $(\mathrm{a}$ significant air pollutant) impacted the snap bean's nutrient uptake and growth. Results showed that plants inoculated with AMF saw significantly less reductions to shoot mineral content (nitrogen, phosphorus, calcium, magnesium) and root mineral content (phosphorus, calcium, magnesium) than those without inoculation.

Recently, Mathur et al. (2018) evaluated the effects of AM inoculation on drought-stressed wheat (Triticum aestivum). Results showed that inoculated wheat performed better than non-inoculated wheat, as inoculated crops saw an increase to their photosynthetic capacity and significant development to their root systems, enhancing water absorption. A similar study also reported beneficial metabolic responses from wheat cultivars under drought stress conditions (Bernardo et al., 2019). In some cases, benefits from AMF inoculation are not significant in alleviating stress from the plant, which suggests the importance of choosing the right inoculum type (Grümberg et al., 2015). Additionally, certain conditions such as having low phosphorus within the soil may negate plant growth benefits from AMF inoculation, resulting in no significant benefit towards biomass production and mineral acquisition (Hack et al., 2019). 
In saline soils, AMF has shown to enhance a plant's salt-tolerance by improving the root's water uptake as well as readjusting the plant's osmotic balance (Evelin et al., 2019; Latef et al., 2016; Bothe, 2012; Azcón \& El-Atrash, 1997; Ruiz Lozano et al., 1995). These mechanisms can increase the crop's overall productivity even under stressed conditions by mitigating harmful effects such as physiological drought and plant toxicity (Juniper \& Abbott, 1993). Improvements to other characteristics such as increased nutrient uptake, nodulation, and protein synthesis balance may also play a role in alleviating salt-stress in plants (Bothe, 2012). It was observed that both salt-stressed and non-stressed alfalfa (Medicago sativa) crops inoculated with AMF had greater yields due to an increase in mycorrhizal colonization, nodulation, and nutrient uptake (Ashrafi, Zahedi, \& Razmjoo, 2014). Additionally, a study by Talaat (2015) revealed that snap beans grown in saline conditions saw reductions to their overall productivity through nutrient content reductions (nitrate and potassium) and protein content. However, inoculating beans with AMF alleviated the reductions seen within these parameters, improving protein synthesis.

\subsubsection{Tripartite Symbiosis}

Application of fertilizers to enhance crop growth and yield can have negative drawbacks associated with economic costs for farmers and the potential risk of runoff of chemicals (i.e., phosphorus or nitrogen) into nearby waterways, leading to the eutrophication of surface water resources (McGuiness, Reid, \& Foo, 2019). Sustainable practices that involve inoculating beneficial microsymbionts such as arbuscular mycorrhizal fungi and rhizobial bacteria on host plants (specifically legumes) have been extensively studied as they provide a low-cost and natural means of improving nutrient 
acquisition in stressed conditions without the need to input chemical fertilizers into the system (Hack et al., 2019; Wang et al., 2011; Al-garni, 2006; Diouf et al., 2005).

Leguminous plants have the benefit of being able to simultaneously form two symbiotic relationships at the same time, specifically with arbuscular mycorrhizal fungi and rhizobia. Previous studies have demonstrated plant growth benefits when dual inoculating the host plant with AMF and plant growth promoting rhizobacteria (PGPR) such as Rhizobium and Bradyrhizobium. By having AMF improve phosphorus acquisition (thus negating the limiting nutrient stress on the plant), it benefits the nitrogen fixing microsymbiont and in turn leads to enhanced nitrogen fixation, plant growth, and ultimately mycorrhizal development (Hodge, 2000).

Results have shown that the legume-Rhizobium-AMF tripartite symbiosis benefits from increased micronutrient uptake (Toma et al., 2017; Chalk et al., 2006) and can mitigate plant growth reductions caused by salinity stress (Diouf et al., 2005). A study by Ren et al., (2016) evaluated the synergetic effects of dual inoculating salt stressed Sesbania cannabina with the AMF species Glomus mosseae and two different rhizobia strains, Agrobacterium pusense and Neorhizobium huautlense. Results showed that the salt-tolerant rhizobia strain along with AMF inoculation improved S. cannabina salt tolerance, with enhancements to nodulation, biological nitrogen fixation, and shoot and root dry biomass.

In a similar study, the dual inoculation of alfalfa (Medicago sativa L.) with G. mosseae and Sinorhizobium meliloti under salinity stress saw increases to AMF inoculation, root nodulation, and overall nutrient uptake when compared to alfalfa grown 
with no inoculation (Ashrafi, Zahedi, \& Razmjoo, 2014). The legume-Rhizobium-AMF symbiosis potential provides a sustainable biological strategy to enhance agricultural productivity under salinity stress and should be further studied to better understand this process.

\subsection{Glomalin-related Soil Protein}

One of the most concerning threats to global sustainability, agricultural productivity, and food security is soil erosion. Globally, soil mean erosion rate is estimated to be 15.2 megagrams per hectare per year $(\mathrm{Mg} / \mathrm{ha} / \mathrm{yr})$, with some continental areas seeing rates as high as 22.1 (South America) and 16.6 (Asia) Mg/ha/yr (Lal, 2003). Soil erosion occurs when soil particles are displaced from the soil surface by certain factors such as wind or water (e.g. runoff and raindrop impact). A common way of assessing how susceptible soils are to erosion is by measuring its aggregate stability (Heikkinen et al. 2019).

Glomalin, a glycoprotein released by the hyphae of AMF, was first discussed by Wright \& Upadhyaya (1996). It was originally assumed no other protein could be extracted because of the harsh extraction methods required for the quantification of glomalin found in soils (Wright \& Upadhyaya, 1998). Further studies revealed that glomalin measurements from soils were not made up solely of glomalin and could contain lipids, humic materials, and other heat-stable proteins not excreted by AMF (Gillespie et al., 2011; Whiffen et al., 2007). The lack of sole glomalin extraction methods and prior debates concerning terminology (Rillig, 2004) resulted in glomalin being defined as glomalin-related soil protein (GRSP) when quantified from soils. This 
terminology is broken down further into two fractions of glomalin; easily extractable glomalin (EEG) and total glomalin (TG), which are characterized by the extraction protocols used.

Since its initial finding, GRSP has received rising attention over the years because of its potential benefits. One of glomalin's key characteristics is its "glue-like" nature in binding soil particles (i.e., aggregates) together. A significant and positive correlation exists between GRSP amounts and the percentage of water-stable aggregates (WSAs), a form of soil aggregate stability and structural measurements (Bedini et al., 2009; Wright et al., 2007; Rillig et al., 2002; Wright \& Upadhyaya, 1998). Aggregate stability is also in part attributed to GRSP because of its hydrophobic and stable nature (Rillig, 2004; Wright \& Upadhyaya, 1998), as it accumulates and has a residence time of 6 to 42 years within the soil (Rillig et al., 2001).

Following its discovery, research has focused mainly on identifying glomalin's role within the soil as well as how GRSP responds under certain conditions. Disruption and reductions to mycorrhizal colonization from tillage (Wright, Starr, \& Paltineanu, 1999), long-term fungicide applications (Gao et al., 2019; Rillig, 2004), and conversion of forested areas into farmland (Rillig et al., 2002) resulted in reduced amounts of GRSP measurements within the soil (Rillig, 2004). However, using certain rotating crop systems increased GRSP concentration and aggregate stability (Wright \& Anderson, 2000).

Other GRSP benefits include a positive influence in soil organic carbon (SOC) sequestration and nutrient absorption (Wang et al., 2017). In some cases, the application of EEG has promoted plant growth by increasing plant height, dry biomass, and stem 
diameter (Wang et. al, 2015). A study by Hammer \& Rillig (2011) that studied the effects of different stressors on glomalin production by AMF indicated that glomalin levels increased positively under high salinity $(\mathrm{NaCl})$ stress. Despite the two decades worth of research since GRSP was first discovered, there still remains a gap within the literature. The potential effects Rhizobium may or may not have on GRSP production, both in natural and saline conditions, have yet to be explored.

\section{METHODOLOGY}

3.1 Site Description and Experimental Design

A potted experiment was conducted within Florida International University's (FIU) Organic Garden shade house (coordinates: $25^{\circ} 45^{\prime} 15.10^{\prime \prime} \mathrm{N}$ and $80^{\circ} 22^{\prime} 48.09^{\prime \prime} \mathrm{W}$ ) between the months of December and January for eight weeks. Commercial 'Caprice' snap beans (bush) were grown in two-gallon nursery pots spaced $0.5 \mathrm{~m} \mathrm{x} 0.5 \mathrm{~m}$ apart and treatments were arranged in a three by three factorial randomized block design. The beans were grown under a set of factorial combinations; (a) inoculant mixture (i.e., whether there was Rhizobium or AMF presence), and (b) three irrigation salinity concentrations for a total of nine treatments (Figure 2). 


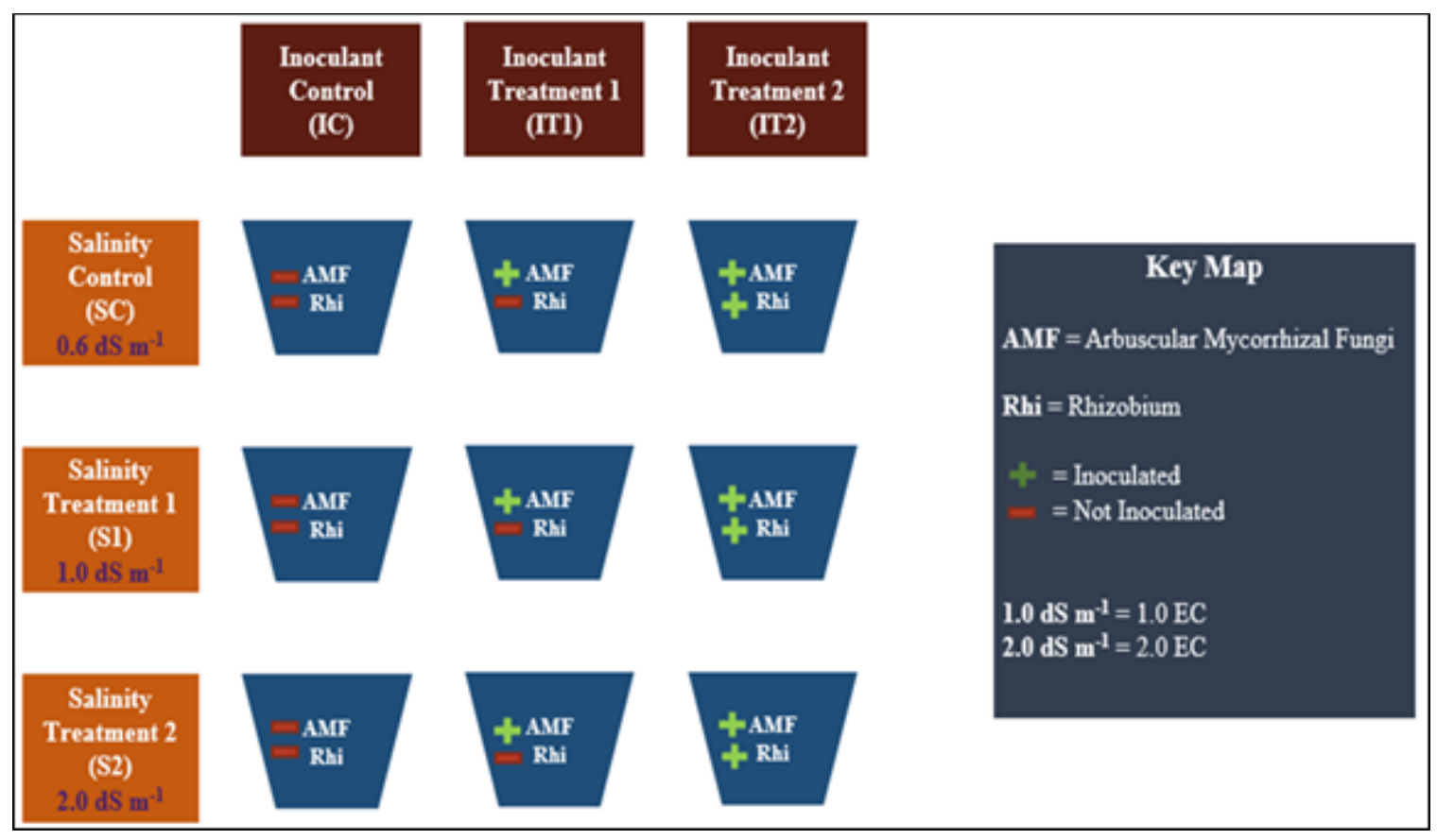

Figure 2 A 3 x 3 factorial randomized block design showcasing the salinity concentration and inoculant mixture combinations in a potted experiment. Each treatment consisted of 10 replicates.

Inoculant mixtures consisted of an inoculant control (IC) - Rhizobium/-AMF, inoculant treatment one (IT1) -Rhizobium/+AMF, and inoculant treatment two (IT2) + Rhizobium/+AMF. Water salinity concentrations were as follows; salinity control (SC) $0.6 \mathrm{dS} \mathrm{m}-1$, salinity treatment one (S1) $1.0 \mathrm{dS} \mathrm{m}{ }^{-1}$, and salinity treatment two (S2) $2.0 \mathrm{dS}$ $\mathrm{m}^{-1}$. All nine treatments had ten replicates for a total of 90 pots in the study and are displayed in Figure 3. 


\begin{tabular}{|c|c|c|}
\hline ICSC & IT1SC & IT2SC \\
\hline No Inoculation & AMF Inoculation & Rhizobium/AMF Inoculation \\
$0.6 \mathrm{dS} \mathrm{m}^{-1}$ & $0.6 \mathrm{dS} \mathrm{m}^{-1}$ & $0.6 \mathrm{dS} \mathrm{m}^{-1}$ \\
\hline ICS1 & IT1S1 & IT2S1 \\
\hline No Inoculation & AMF Inoculation & Rhizobium/AMF Inoculation \\
$1.0 \mathrm{dS} \mathrm{m}^{-1}$ & $1.0 \mathrm{dS} \mathrm{m}^{-1}$ & $1.0 \mathrm{dS} \mathrm{m}^{-1}$ \\
\hline ICS2 $^{\text {No Inoculation }}$ & IT1S2 & IT2S2 \\
\hline $2.0 \mathrm{dS} \mathrm{m}^{-1}$ & AMF Inoculation & Rhizobium/AMF Inoculation \\
\hline & $2.0 \mathrm{dS} \mathrm{m}^{-1}$ & $2.0 \mathrm{dS} \mathrm{m}^{-1}$ \\
\hline
\end{tabular}

Figure 3 The nine treatments of the potted experiment at Florida International University. Treatments consisted of a $3 \times 3$ factorial randomized block design.

\subsection{Planting Methods}

Snap beans in this study were planted using modified methods from Al-Garni (2006) and Scholberg \& Locascio (1999). All pots were filled with Sungro Professional Growing Mix Metro-Mix® 830 potting soil along with two tablespoons of Root Naturally Endo Mycorrhizae containing a mixture of various endomycorrhizal fungi species (Glomus intraradices, Glomus mosseae, Glomus aggregatum, and Glomus etunicatum) $5.0 \mathrm{~cm}$ below the soil surface. Root Naturally Endo Mycorrhizae was administered only to treatments that contained AMF inoculation (i.e., IT1SC, IT2SC, IT1S1, IT2S1, IT1S2, and IT2S2). 'Caprice' snap bean seeds were soaked in non-chlorinated water before being inoculated with GUARD-N Rhizobium seed inoculant for treatments IT2SC, IT2S1, and IT2S2. GUARD-N Rhizobium seed inoculant had a mixture of the following species; Bradyrhizobium sp. (Vigna), Bradyrhizobium japonicum, Rhizobium leguminosarum biovar phaseoli, and Rhizobium leguminosarum biovar viceae. 
After inoculation, seeds were left to dry for three minutes prior to immediate planting. Four seeds per pot were planted $5.0-10.0 \mathrm{~cm}$ apart $2.05 \mathrm{~cm}$ deep within the soil (Figure 4.a). After emergence, seedlings were thinned to one per pot. All pots were initially irrigated with water from the organic garden $\left(0.6 \mathrm{dS} \mathrm{m} \mathrm{m}^{-1}\right)$ every two days at $25 \%$ of the soil's water holding capacity (Figure 4.b). To provide additional nutrients, $11 \mathrm{~mL}$ of Hoagland's solution at $1 / 2$ strength without ammonium phosphate was prepared (AlGarni, 2006) and administered to each pot once a week (Figure 4.c).
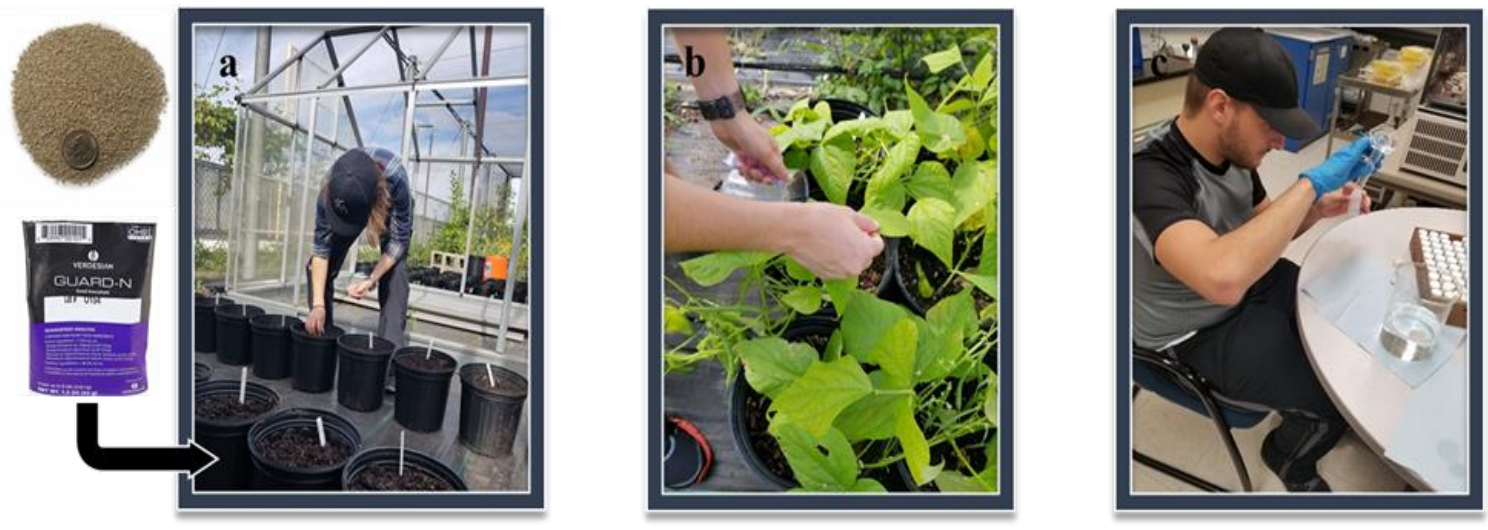

Figure 4 Planting methods: (a) inoculation of soil and seeds prior to planting, (b) irrigation of beans, and (c) Hoagland solution preparation.

Salinity treatments began 26 days after planting (DAP) to allow for enhanced AMF root colonization and establishment. After 26 days, beans were irrigated following protocols from Hamoui et al. (2001) with modifications. Pots were irrigated with $200 \mathrm{~mL}$ of the corresponding salinity treatment ( $\mathrm{SC}, \mathrm{S} 1$, or $\mathrm{S} 2$ ) three times a week for the duration of the growth period. Salinized irrigation water was prepared by mixing water from the organic garden and sodium chloride in buckets until proper EC values were 
reached. Because of the presence of leaf miners midway into the experiment, a one-time application of neem oil was sprayed across all treatments.

\subsection{Plant Growth Data Collection}

\subsubsection{Plant Height, Leaf Chlorophyll Concentration, and Bean Yield}

To assess the effect of dual inoculation and salinity concentration on crop growth, bean height $(\mathrm{cm})$ was measured following protocols from Scholberg \& Locascio (1999) with modifications. Plant height was measured every two weeks after planting for a total of four measurements (Figure 5.a). For better accuracy, beans were measured from the lowest stem node up until the uppermost shoot tip. Similarly, the average leaf chlorophyll concentration of developed, upper leaves was determined using the Soil-Plant Analyses Development (SPAD) 502 Plus Chlorophyll Meter every two weeks for a total of four readings (Figure 5.b) following Freidenreich et al. (2019) protocols. Leaf chlorophyll concentration is a good general indicator for crop health and can be assessed in a quick and non-destructive manner (Freidenreich et al., 2019). Furthermore, leaf nitrogen and chlorophyll content are considered to be strongly correlated and would indicate whether a plant's leaves are likely to have higher or lower nitrogen content (Ling, Huang, \& Jarvis, 2011). Total fresh bean yield was acquired prior to crop termination for all nine treatments (Scholberg \& Locascio, 1999). Bean yield was taken by picking all of the beans that were growing in each treatment and were weighed immediately thereafter (Figure 5.d). Because of this, the total bean yield is considered fresh and moisture content was not considered. 

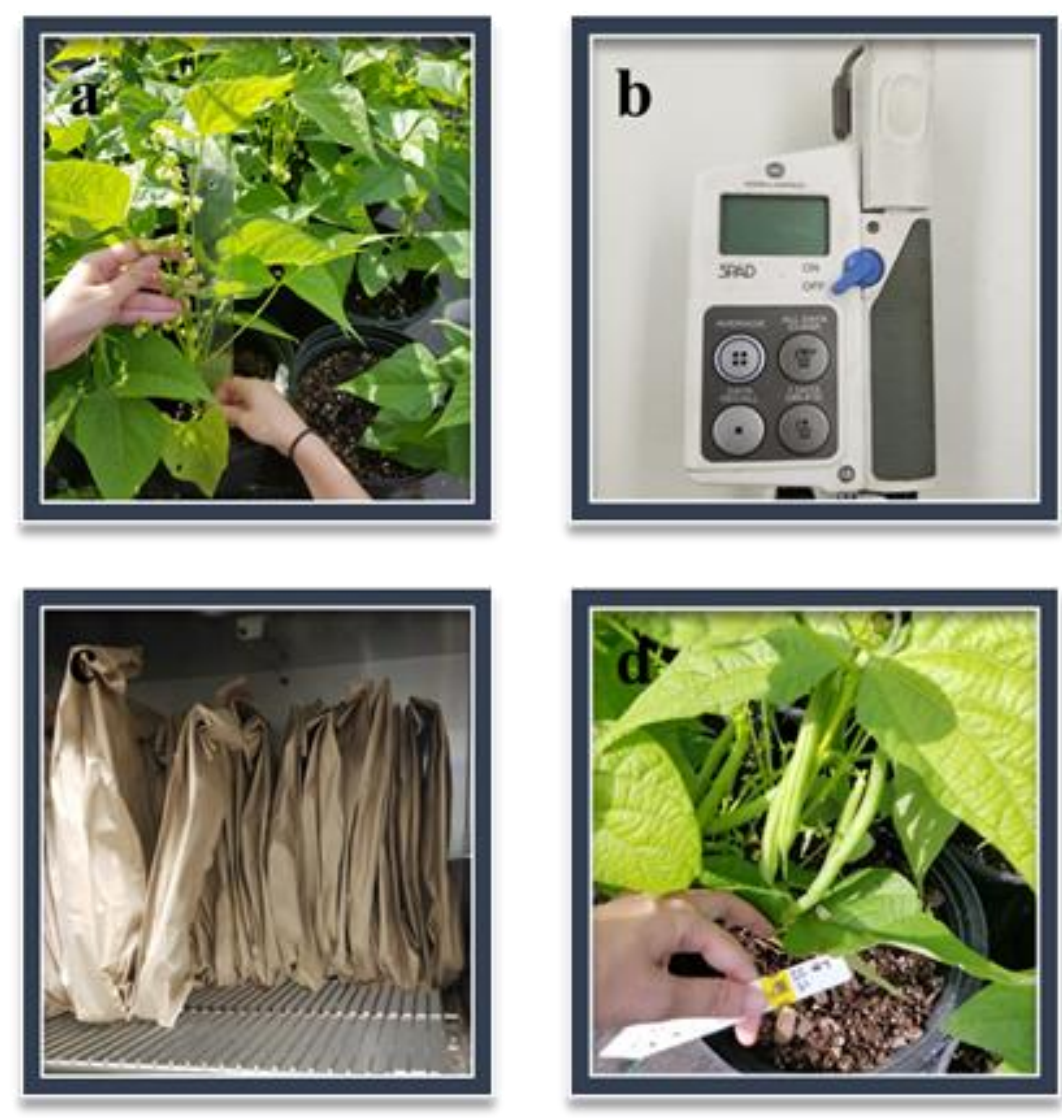

Figure 5 Plant growth data collection: a) Plant height of snap beans being taken b) SPAD meter used for chlorophyll content measurements c) shoot and root samples were dried at $72{ }^{\circ} \mathrm{C}$ for 3 days and c) total bean yield harvested 56 DAP and weighed.

\subsubsection{Shoot and Root Dry Biomass}

Following the growth period, all 90 replicates were terminated, and fresh shoot and root samples were collected 58 DAP following Scholberg \& Locascio (1999) protocols. Shoot samples consisted of both stem and leaves and were taken from the first node up. Roots were carefully washed to remove soil particles and all samples were stored at $4{ }^{\circ} \mathrm{C}$ until further analysis. To evaluate dry biomass, all treatment replicate samples were dried at $70{ }^{\circ} \mathrm{C}$ for three days prior to weighing (Figure 5.c). 


\subsubsection{Soil and Other Data}

To assess whether the factorial combinations of inoculation type or salinity levels had an influence on soil characteristics, additional soil parameters were analyzed. Primary, intermediate, and post-harvest soil $\mathrm{pH}$ measurements were taken during the first, fourth, and eighth week of the growth period using a Fieldscout pH 400 meter. A total of eight weekly readings for soil moisture, temperature, bulk EC, and pore water EC were measured using the Thermo Scientific Orion Star A329 Portable meter prior to the irrigation or Hoagland solution applications into the soil. These measurements utilized all ten potted replicates for each of the nine treatments.

After terminating the snap beans, soil samples were randomly collected (i.e., samples $\# 1,4,7,8,10)$ from five of the ten replicates of each of the nine treatments. The 45 soil samples were stored at $4{ }^{\circ} \mathrm{C}$ until further analysis. Root samples were collected in a similar manner from randomly selected pots for future root analysis.

Quantifying the AM colonization percent infection within the roots was done by following the protocols of McGonigle et al. (1990) with some modifications. After completion of the bean growth period, roots were carefully washed in order to remove any remaining soil particles. Thin root hairs were collected and submerged within microcentrifuge tubes filled with $10 \%$ potassium hydroxide solution $(\mathrm{KOH})$. After submergence, samples were kept in an oven at $70{ }^{\circ} \mathrm{C}$ for two hours before they were rinsed with deionized (DI) water. After rinsing, to remove any potential root tannins, samples were submerged in Alkaline $\mathrm{H}_{2} \mathrm{O}_{2}$ for half an hour after which they were rinsed once more with DI water. Samples were then immersed in $1 \%$ hydrochloric acid $(\mathrm{HCl})$ 
for 30 minutes prior to root staining, where samples were submerged within a $0.05 \%$ Trypan blue and lactoglycerol solution for $20 \mathrm{~min}$ at $70{ }^{\circ} \mathrm{C}$. After rinsing in DI water, root slides for each of the nine treatment replicates were made, creating a total of 45 slides. Root slides were created by placing 20 roots of each sample onto a slide containing a drop of glycerol solution (100 mL glycerol and $100 \mathrm{~mL}$ lactic acid). Once created, slides were viewed under a light microscope and each individual root was classified as either colonized (Figure 6.a) when vesicles were present, or uncolonized (Figure 6.b) in the absence of vesicles. To calculate the percentage of AM colonization, the following formula was used:

$$
\frac{\# \text { of Colonized Roots }}{\text { Total \# of Roots }} \times 100 \%
$$




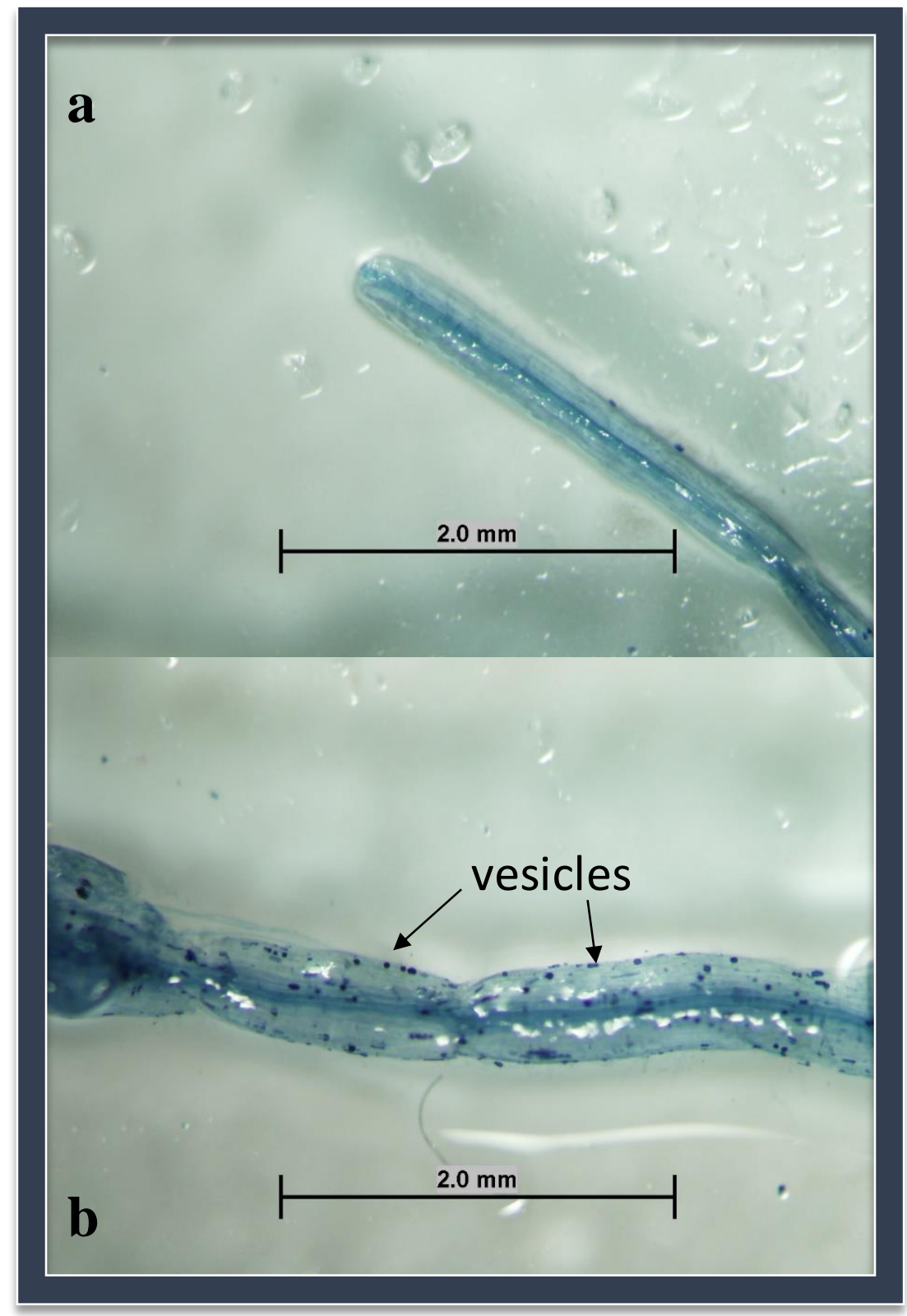

Figure 6 Snap bean roots stained with Trypan blue: a) non-infected root and b) root colonized by arbuscular mycorrhizal fungi. 


\subsection{Glomalin-related Soil Protein}

\subsubsection{Glomalin-related Soil Protein Extraction (GRSP)}

To extract glomalin-related soil protein, soil samples from $5^{\circ} \mathrm{C}$ replicates of all nine treatments (e.g. ICSC 1, 4, 7, 8, and 10) were randomly selected, dried at 50 for 24 hours, and sieved $(1.0-2.0 \mathrm{~mm})$ prior to protein extraction following the protocols of Wright and Upadhyaya (1998) with modifications (Wang et al., 2017). Easily-extractable GRSP (EEG) was extracted from $0.5 \mathrm{~g}$ soil samples by adding $4 \mathrm{~mL}$ of $20 \mathrm{mmol} \mathrm{L}^{-1}$ sodium citrate ( $\mathrm{pH} 7.0$ ) solution followed by autoclaving at $121{ }^{\circ} \mathrm{C}$ for $30 \mathrm{~min}$. Total glomalin-related soil protein (TG) was extracted by adding $4 \mathrm{~mL}$ of $50 \mathrm{mmol} \mathrm{L}^{-1}$ sodium citrate ( $\mathrm{pH} 8.0$ ) solution to $0.1 \mathrm{~g}$ soil samples prior to autoclaving at $121^{\circ} \mathrm{C}$ for $60 \mathrm{~min}$. For both EEG and TG, the supernatant was collected by centrifugation at $3000-4000 \mathrm{~g}$ for 12 min (Figure 7.a) and stored at $4{ }^{\circ} \mathrm{C}$. For TG, the procedure was repeated eight times and the supernatant from each cycle was pooled together (Figure 7.b) until the reddish-brown color attributed to GRSP disappeared and the coloring became transparent (Figure 7.c). 

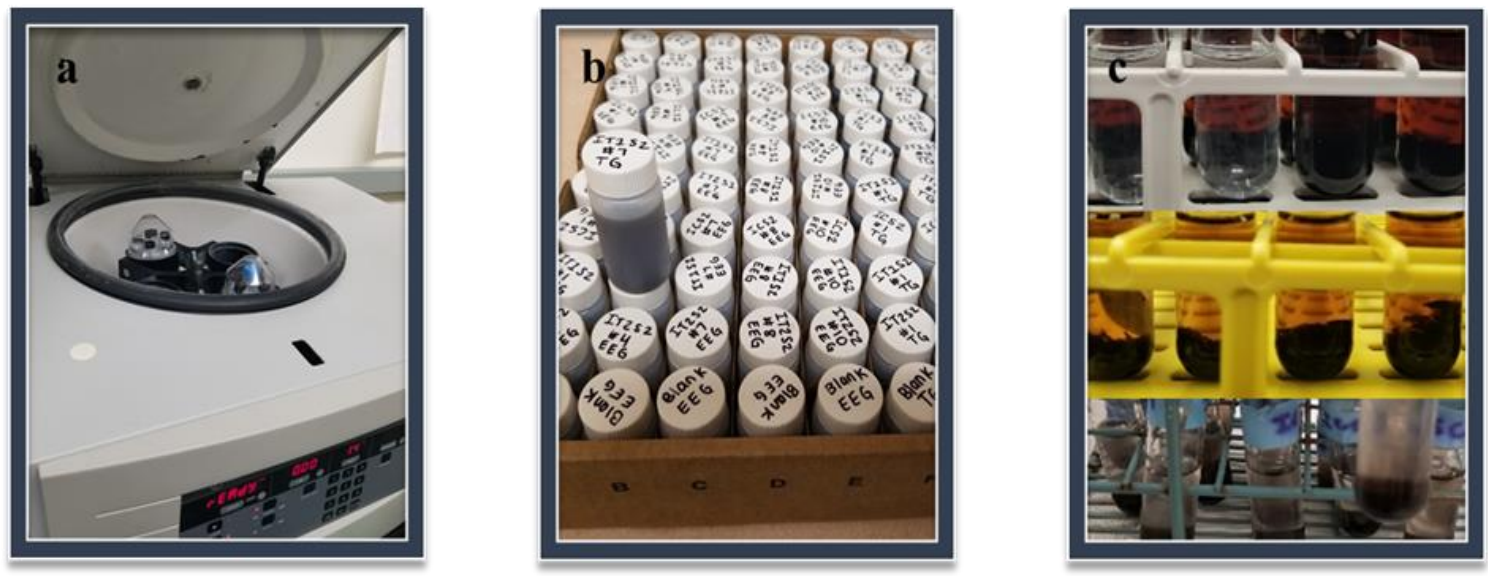

Figure 7 GRSP extraction methods: (a) centrifugation of soil samples with sodium citrate, (b) supernatant collected and pooled together, and (c) supernatant during the first, fourth, and eighth extraction cycle.

\subsubsection{Glomalin-related Soil Protein Measurement}

The protein concentration within the supernatant was then determined by following Thermo Scientific Pierce ${ }^{\mathrm{TM}}$ Coomassie Plus Bradford Assay Kit with the bovine serum albumin (BSA) used as the standard. Figure 8 represents how microplate columns were arranged and filled with $5 \mu \mathrm{L}$ of blank samples (sodium citrate 20 or 50 mmol), $5 \mu \mathrm{L}$ of sample solutions (i.e., ICSC $1,4,7$, etc.), and $5 \mu \mathrm{L}$ of standard solution. Once prepared, $250 \mu \mathrm{L}$ of Coomassie Plus Reagent was dispensed into all plate wells and left to incubate for $10 \mathrm{~min}$ before the protein absorbance was measured at $595 \mathrm{~nm}$ (Wang et al., 2017). 


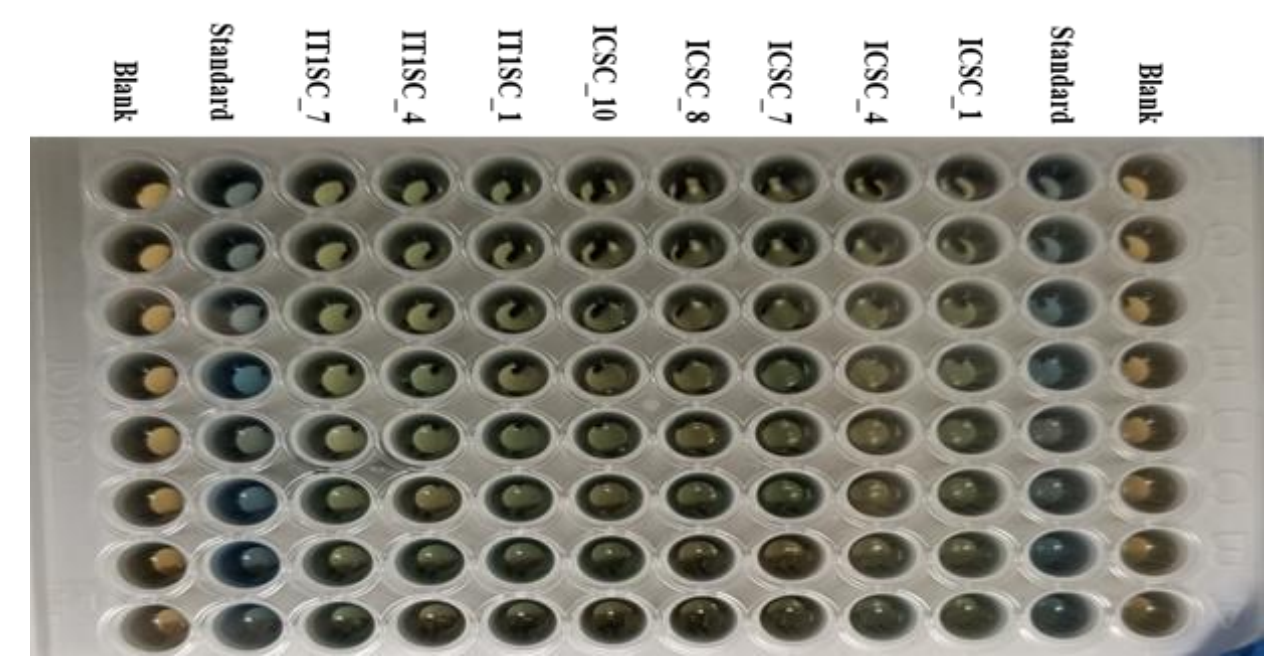

Figure 8 General blank, standard, and GRSP sample arrangement for microplate reader to determine GRSP concentration after using the Bradford Assay. To determine GRSP concentration, five replicates for each of the nine treatments were analyzed.

\subsection{Aggregate Stability}

The stable aggregate content of each treatment's soil was tested using the aggregation apparatus and methodologies of Patton et al. (2001) with an additional step added to account for high organic matter content within the soil. Dried soil samples were sieved from 1.0 to $2.0 \mathrm{~mm}$ and weighed $3.00 \pm 0.05 \mathrm{~g}$ ( $W_{\text {or }}=$ original sample weight $)$. Sieves sized $0.5 \mathrm{~mm}$ were weighed ( $W_{e}=$ weight of empty sieves) before samples were carefully poured and spread out in an equal manner. Sieves were then placed upon the aggregation apparatus filled with $5 \mathrm{~L}$ of deionized water and left to settle overnight. Once settled, samples were agitated by carefully lifting the aggregation rack 20 times within 40 $\mathrm{s}$ before drying at $105^{\circ} \mathrm{C}$ for $2 \mathrm{~h}$. Dried samples were weighed $\left(W_{c}=\right.$ sieve, aggregate, and 0.5 to $1.0 \mathrm{~mm}$ sand particle weight) before being placed once more unto the aggregation apparatus, after which $3.0 \mathrm{~g}$ of hexametaphosphate was added to the deionized water to disperse soil particles and remove discrete sand particles sized from 
0.5 to $1.0 \mathrm{~mm}$, which could cause inaccuracies in aggregate stability because of weight inflation. Samples were agitated within regular intervals for $30 \mathrm{~min}$ and carefully washed with deionized water before being dried at $105{ }^{\circ} \mathrm{C}$ for $2 \mathrm{~h}$. After removing the samples from the oven, sieves were once again weighed $\left(W_{s}=\right.$ sieve and 0.5 to $1.0 \mathrm{~mm}$ sand particle weight). Following the method by Patton et al. (2001), aggregate content was calculated using the following formulas:

$$
W_{c}-W_{e}=W_{a s}
$$

Where $\mathrm{W}_{\text {as }}$ stands for sand and aggregate weight,

$$
W_{s}-W_{e}=W_{s d}
$$

Where $\mathrm{W}_{\text {sd }}$ stands for sand weight,

$$
\text { Stable aggregate content }(\%)=\left(\frac{W_{a s}-W_{s d}}{W_{o r}-W_{s d}}\right) \times 100 \%
$$

As a result of potentially high amounts of organic content within the soil, an additional step was added to account for the stable aggregate content inaccuracies this substantial concentration of organic material could cause. Sand and aggregate weight samples $\left(\mathrm{W}_{\mathrm{s}}\right)$ samples were distributed into pre-weighed crucibles $\left(W_{c r}=\right.$ weight of empty crucibles) and weighed ( $W_{\text {com }}=$ weight of the crucible, sand particles, and organic matter). Samples were then placed within a furnace at $550{ }^{\circ} \mathrm{C}$ for 3 and $1 / 2$ h to burn $90 \%$ of the organic content within the soil. Following that, samples were sieved $(0.5 \mathrm{~mm})$ to 
remove burnt organic matter before being reweighed again $\left(\mathrm{W}_{\mathrm{ss}}=\right.$ weight of sand particles after accounting for organic matter).

\subsection{Data Analysis}

Data analysis was performed using the SAS 9.4 (SAS Institute, NC). The tests performed were two-way ANOVA because of the $3 \times 3$ factorial design and the two levels (i.e., inoculation type and salinity content). Plant height, biomass, and chlorophyll content from the three inoculant and salinity treatments were analyzed to see if there is a significant difference in plant growth. Easily extractable and total glomalin were compared between the different inoculation and salinity treatments to see whether there was a significant difference in GRSP production. Data were considered to be significant when $\mathrm{p}<0.05$.

\section{RESULTS AND DISCUSSION}

4.1 ANOVA and Table for Total Bean Yield, Root and Shoot Dry Weight and Ratios

Plant growth response of snap beans under varying inoculation types $(\mathrm{IC}=$ no inoculation, $\mathrm{IT} 1=\mathrm{AMF}$, and IT2 $=\mathrm{AMF} /$ Rhizobium $)$ and salinity levels $\left(\mathrm{SC}=0.6 \mathrm{dS} \mathrm{m}{ }^{-}\right.$

${ }^{1}, \mathrm{~S} 1=1.0 \mathrm{dS} \mathrm{m}{ }^{-1}, \mathrm{~S} 2=2.0 \mathrm{dS} \mathrm{m}{ }^{-1}$ ) was evaluated by measuring parameters such as plant height, total bean yield, dry shoot and root weight, and leaf chlorophyll concentration (Table 2). 
Table 2 Effect of salinity level and inoculation type on snap bean characteristics

\begin{tabular}{llcccc}
\hline Treatment & $\begin{array}{c}\text { Plant Height } \\
\text { Week 8 }(\mathbf{c m})\end{array}$ & $\begin{array}{c}\text { Total Bean } \\
\text { Yield }(\mathbf{g})\end{array}$ & $\begin{array}{c}\text { Shoot Dry } \\
\text { Weight }(\mathbf{g})\end{array}$ & $\begin{array}{c}\text { Root Dry } \\
\text { Weight }(\mathbf{g})\end{array}$ & $\begin{array}{c}\text { Shoot } \\
\text { to } \\
\text { Root } \\
\text { Ratio }\end{array}$ \\
\hline ICSC & $26.48^{\mathrm{c}} \pm 2.76$ & $44.20^{\mathrm{ab}} \pm 7.47$ & $5.57^{\mathrm{ab}} \pm 0.74$ & $1.60^{\mathrm{a}} \pm 0.64$ & 3.48 \\
IT1SC & $27.15^{\mathrm{c}} \pm 2.91$ & $23.93^{\mathrm{c}} \pm 7.16$ & $3.99^{\mathrm{bc}} \pm 0.97$ & $1.44^{\mathrm{a}} \pm 0.35$ & 2.77 \\
IT2SC & $26.78^{\mathrm{c}} \pm 4.91$ & $33.29^{\mathrm{bc}} \pm 9.71$ & $5.61^{\mathrm{a}} \pm 1.21$ & $1.53^{\mathrm{a}} \pm 0.46$ & 3.67 \\
ICS1 & $28.53^{\mathrm{bc}} \pm 2.33$ & $57.26^{\mathrm{a}} \pm 8.00$ & $6.53^{\mathrm{a}} \pm 1.58$ & $1.52^{\mathrm{a}} \pm 0.28$ & 4.30 \\
IT1S1 & $31.01^{\mathrm{abc}} \pm 2.44$ & $27.97^{\mathrm{c}} \pm 5.21$ & $5.03^{\mathrm{abc}} \pm 0.93$ & $1.59^{\mathrm{a}} \pm 0.25$ & 3.16 \\
IT2S1 & $30.83^{\mathrm{abc}} \pm 2.66$ & $43.57^{\mathrm{b}} \pm 10.38$ & $6.09^{\mathrm{a}} \pm 0.87$ & $1.51^{\mathrm{a}} \pm 0.22$ & 4.03 \\
ICS2 & $29.52^{\mathrm{abc}} \pm 4.15$ & $35.49^{\mathrm{bc}} \pm 14.83$ & $4.96^{\mathrm{abc}} \pm 1.29$ & $1.27^{\mathrm{a}} \pm 0.25$ & 3.91 \\
IT1S2 & $32.31^{\mathrm{ab}} \pm 3.74$ & $30.36^{\mathrm{c}} \pm 8.56$ & $3.71^{\mathrm{c}} \pm 1.30$ & $1.44^{\mathrm{a}} \pm 0.29$ & 2.58 \\
IT2S2 & $33.80^{\mathrm{a}} \pm 3.95$ & $35.36^{\mathrm{bc}} \pm 6.03$ & $5.19^{\mathrm{abc}} \pm 0.71$ & $1.42^{\mathrm{a}} \pm 0.29$ & 3.65 \\
\hline Treatm & & & & & \\
\hline
\end{tabular}

Treatments consist of inoculation type (IC = No inoculation, IT1 = Mycorrhizal, IT2 = Rhizobium + Mycorrhizal) and salinity levels ( $\mathrm{SC}=$ Salinity control $0.6 \mathrm{dS} \mathrm{m} \mathrm{m}^{-1} \mathrm{EC}, \mathrm{S} 1=1.0 \mathrm{dS} \mathrm{m}^{-1} \mathrm{EC}$, and $\left.\mathrm{S} 2=2.0 \mathrm{dS} \mathrm{m}^{-1} \mathrm{EC}\right)$. Values are expressed as mean \pm Standard Deviation. Each treatment consisted of $n=10$. Means within a column followed by the same letter are not significantly different at $\mathrm{P}<0.05$.

Prior to plant termination, bean height was measured periodically every two weeks with statistical analysis performed on final plant height (Table 2). The greatest mean heights were observed in IT2S2 $(33.80 \mathrm{~cm})$, IT1S2 $(32.31 \mathrm{~cm})$, and IT1S1 $(31.01$ $\mathrm{cm})$. Notably, snap beans in non-stressed (SC) conditions showed the worst growth performance in terms of plant height, with the lowermost height values occurring in ICSC $(26.48 \mathrm{~cm})$, IT2SC $(26.78 \mathrm{~cm})$, and IT1SC $(27.15 \mathrm{~cm})$. While inoculation and salinity did not have an effect on height, there was a significant difference between non-stressed (ICSC, IT1SC, and IT2SC) and highly stressed snap bean treatments with inoculation 
(IT1S2, IT2S2). The significantly low height measurements seen in non-stressed snap beans may be potentially attributed to a lack of sunlight during the initial part of the experiment. An issue with positioning affected the light availability of beans in nonstressed conditions for two weeks after planting, increasing shade duration for these treatments overall. Because of a lack of sunlight during this period, height measurements for treatments with grown under the salinity control could be skewed unfavorably.

Additional parameters such as total bean yield, shoot and root dry weight for all nine treatments is presented in table 2. Treatments ICS1 (57.26 g), ICSC (44.20 g), and IT2S1 (43.57 g) had the greatest mean total bean yield while treatments IT1SC (23.93 g), IT1S1 (27.97 g), and IT1S2 (30.36 g) had the lowermost yield. Across all three salinity levels, snap beans inoculated with AMF had reduced mean yields when compared to their respective non-inoculated and co-inoculated counterparts. These reductions were significant in non-stressed conditions, as IT1SC significantly underperformed when compared to ICSC's yield. Further observations indicated that when irrigated with slightly brackish water $\left(1.0 \mathrm{dS} \mathrm{m} \mathrm{m}^{-1}\right)$, total bean yield for all three corresponding inoculation treatments (ICS1, IT1S1, and IT1S1) were significantly different. However, this significance in bean yield was not witnessed when beans were irrigated with brackish water $\left(2.0 \mathrm{dS} \mathrm{m}^{-1}\right)$. Contrary to our expected results for beans irrigated with $1.0 \mathrm{dS} \mathrm{m} \mathrm{m}^{-1}$ EC, the highest mean yield was witnessed in non-inoculated snap beans (ICS1 = 57.26 g) followed by co-inoculation (IT2S1 = 43.57 g) and single AMF inoculation (IT1S1 = $27.97 \mathrm{~g})$. While symbiotic relationships have the potential to improve the plant's water and nutrient availability, AMF and Rhizobium are active consumers (Borkowska, 2002) and require carbon from the host plant, which may cause a potential strain. 
Bean shoot dry weight was higher for plants with co-inoculation

(AMF/Rhizobium) as well as no inoculation than for those with only AMF across all three salinity levels (Table 2). In non-stressed conditions $\left(0.6 \mathrm{dS} \mathrm{m}^{-1}\right)$, co-inoculated beans had significantly higher shoot dry weight measurements than those inoculated with AMF

only. However, there were no significant differences observed at threshold salinity (1.0 $\left.\mathrm{dS} \mathrm{m}^{-1}\right)$ and higher levels $\left(2.0 \mathrm{dS} \mathrm{m}^{-1}\right)$. Similarly, inoculation type and salinity levels did not have an effect on root dry weight. The highest measurements were observed in ICSC (1.60 g), IT1S1 (1.59 g), IT2SC (1.53 g) and lowermost in ICS2 (1.27 g), IT2S2 (1.42 g), and IT1S2 (1.44g). Overall, the lack of significant salt-stress effect on biomass may be due to the short duration of the salinity treatments (4 weeks). A more pronounced effect may have been seen at the later stages.

\subsection{Soil Bulk and Pore Water EC}

Figure 9 depicts the mean EC values for all nine treatments (ICSC, IT1SC, IT2SC, ICS1, IT1S1, IT2S1, ICS2, IT1S2, and IT2S2) across an eight-week growth period. Prior to salinity treatment applications, the first half of the experiment (weeks 1 4) beans were irrigated with fresh water $\left(0.6 \mathrm{dS} \mathrm{m} \mathrm{m}^{-1}\right)$. Initial pore water EC values for week 1 were the lowest in treatment ICSC $\left(2.19 \mathrm{dS} \mathrm{m}^{-1}\right)$ and the highest in treatment IT2S2 (2.87 $\left.\mathrm{dS} \mathrm{m}^{-1}\right)$. Soil bulk EC values were noticeably lower, with values ranging from $0.20 \mathrm{dS} \mathrm{m}^{-1}$ (ICS2) to $0.26 \mathrm{dS} \mathrm{m}^{-1}$ (ICSC). During the following weeks in which treatments were not stressed with salt-rich water, there was a noticeable trend of decreasing salinity across all treatments. This decreasing salinity trend continued until week 4, where measurements reached similar values for their respective parameters. Week four saw the least difference in values, with pore water EC ranging from $0.88 \mathrm{dS}$ 
$\mathrm{m}^{-1}$ (IT1S2) to $1.22 \mathrm{dS} \mathrm{m}^{-1}$ (IT2S2) and soil bulk EC from $0.07 \mathrm{dS} \mathrm{m}^{-1}$ (IT1SC) to 0.10 $\mathrm{dS} \mathrm{m} \mathrm{m}^{-1}$ (IT2S2). A decrease in soil and pore water salinity during the first half of the experiment can be attributed to salts being flushed down the soil profile rather than accumulating.

The second half of the experiment began 26 days after planting and salinity applications were first administered. Beans were irrigated with $200 \mathrm{~mL}$ of varying salinity levels $\left(0.6,1.0\right.$, and $\left.2.0 \mathrm{dS} \mathrm{m}^{-1} \mathrm{EC}\right)$ three times a week until crop termination. An immediate impact was seen as salinity values increased in both parameters, specifically for treatments that were irrigated with 1.0, and $2.0 \mathrm{dS} \mathrm{m}^{-1} \mathrm{EC}$ levels. As time passed, there was a clear distinction between salinity values. Final pore water EC values during week 8 were the highest in treatment ICS2 $\left(2.21 \mathrm{dS} \mathrm{m}^{-1}\right)$ followed by IT2S2 $\left(2.14 \mathrm{dS} \mathrm{m} \mathrm{m}^{-1}\right)$ and IT1S2 $\left(2.00 \mathrm{dS} \mathrm{m}^{-1}\right)$. Treatments that were irrigated with $1.0 \mathrm{dS} \mathrm{m}^{-1}$ did not see as much of a drastic increase in their salinity levels; ICS1 $\left(1.68 \mathrm{dS} \mathrm{m}^{-1}\right)$, IT2S1 $\left(1.50 \mathrm{dS} \mathrm{m}^{-}\right.$ $\left.{ }^{1}\right)$, and IT1S1 (1.19 dS m$\left.{ }^{-1}\right)$. However, treatments that were irrigated with fresh water quality $\left(0.6 \mathrm{dS} \mathrm{m}^{-1}\right)$ saw very little change in salinity levels; IT2SC $\left(0.97 \mathrm{dS} \mathrm{m}^{-1}\right)$, ICSC $\left(0.94 \mathrm{dS} \mathrm{m}^{-1}\right)$, and IT1SC $\left(0.90 \mathrm{dS} \mathrm{m}^{-1}\right)$. A similar trend was seen in soil bulk EC, with the highest values found in both IT2S2 and ICS2 $\left(0.21 \mathrm{dS} \mathrm{m}^{-1}\right)$ followed by IT1S2 $(0.19$ $\mathrm{dS} \mathrm{m}{ }^{-1}$ ). Treatments irrigated with $0.6 \mathrm{dS} \mathrm{m}^{-1}$ had the lowest EC values, with the lowermost measurement seen in treatment IT2SC $\left(0.07 \mathrm{dS} \mathrm{m}^{-1}\right)$. Overall, beans that were inoculated with AMF and irrigated with the highest salinity had lower salinity in both soil bulk and pore water salinity during week 8 . 
a

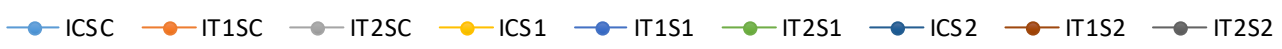

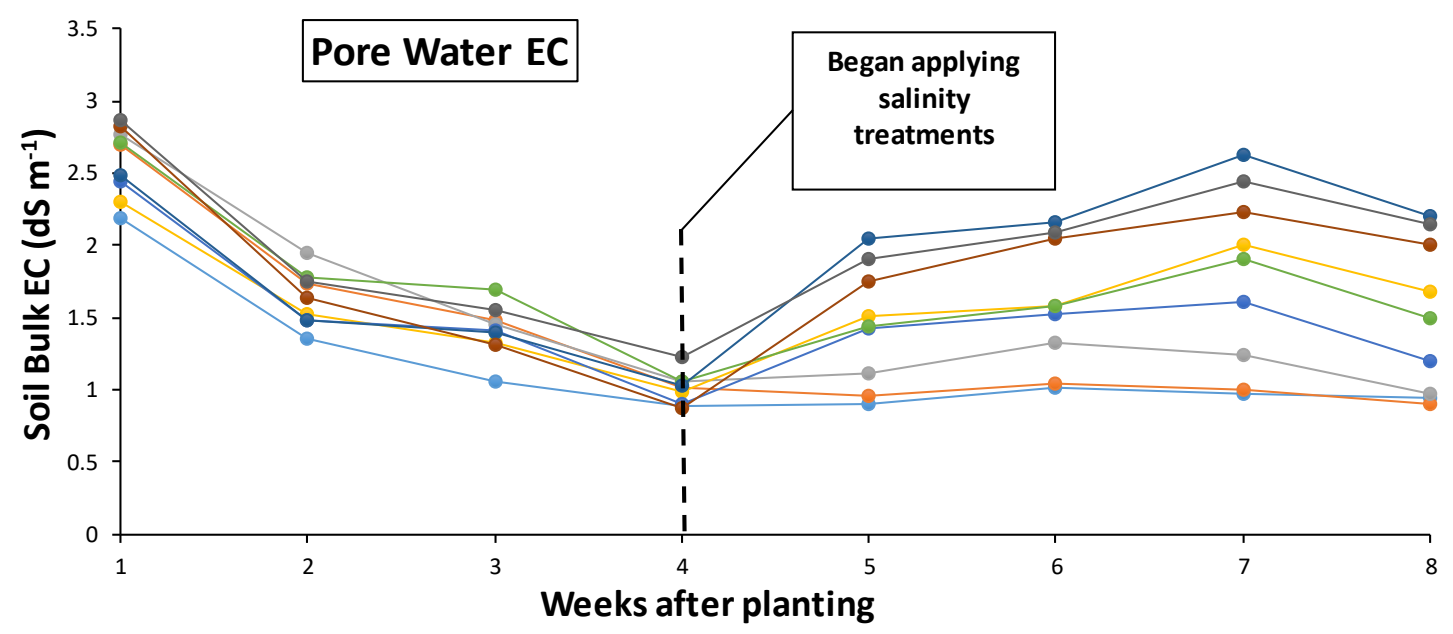

b

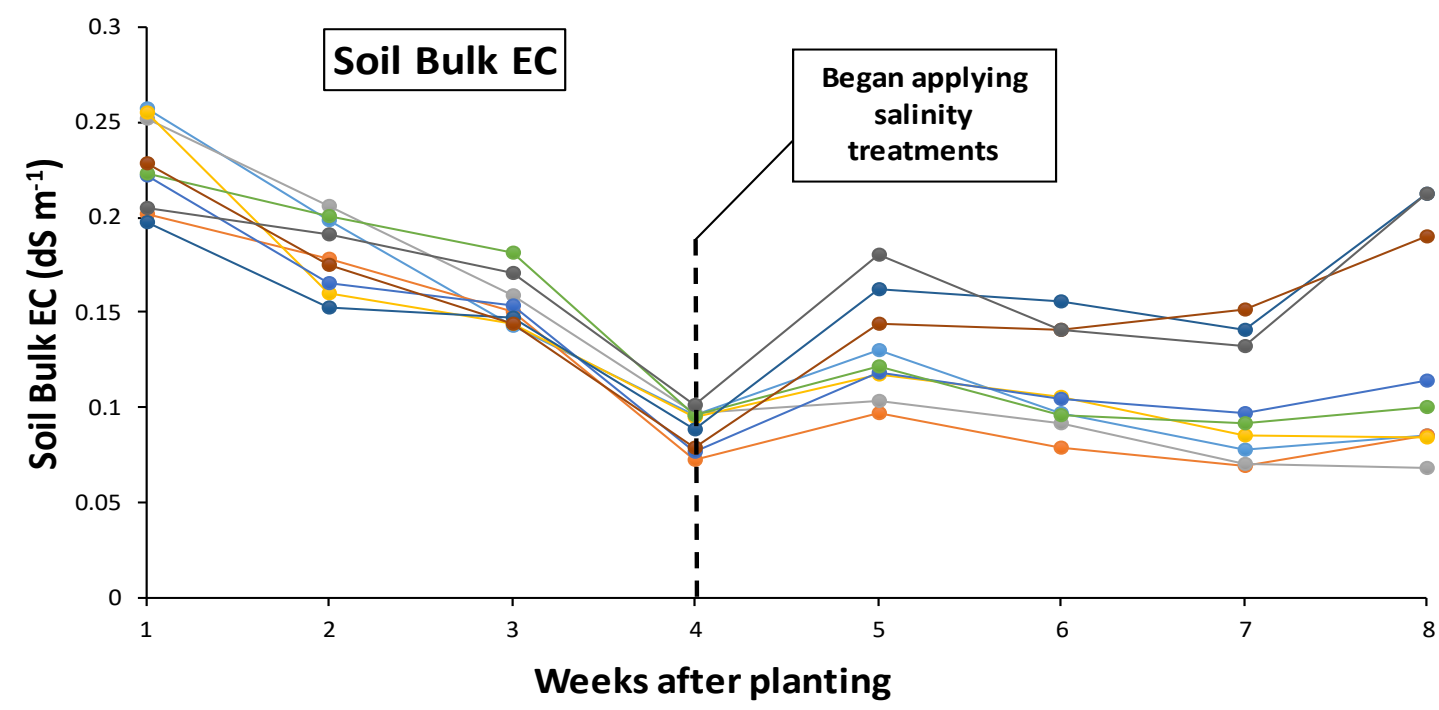

Figure 9 Scatter line graph depicting a) how the pore water EC in the soil changes over time and b) how soil bulk EC changes over time. Treatments consist of inoculation type (IC $=$ No inoculation, IT1 = Mycorrhizal, IT2 $=$ Rhizobium + Mycorrhizal) and salinity levels (SC = Salinity control $0.6 \mathrm{dS} \mathrm{m}^{-1} \mathrm{EC}, \mathrm{S} 1=1.0 \mathrm{dS} \mathrm{m}^{-1} \mathrm{EC}$, and S2 $=2.0 \mathrm{dS} \mathrm{m}^{-1} \mathrm{EC}$ ). The dashed line represents when snap beans were first irrigated with their corresponding salinity treatment (i.e., $0.6,1.0$ and $2.0 \mathrm{dS} \mathrm{m}^{-1} \mathrm{EC}$ ). Values are expressed as mean and each treatment consisted of $\mathrm{n}=$ 10. 
The second half of the experiment began 26 days after planting and salinity applications were first administered. Beans were irrigated with $200 \mathrm{~mL}$ of varying salinity levels $\left(0.6,1.0\right.$, and $\left.2.0 \mathrm{dS} \mathrm{m}^{-1} \mathrm{EC}\right)$ three times a week until crop termination. An immediate impact was seen as salinity values increased in both parameters, specifically for treatments that were irrigated with 1.0, and $2.0 \mathrm{dS} \mathrm{m}^{-1} \mathrm{EC}$ levels. As time passed, there was a clear distinction between salinity values. Final pore water EC values during week 8 were the highest in treatment ICS2 $\left(2.21 \mathrm{dS} \mathrm{m}^{-1}\right)$ followed by IT2S2 $\left(2.14 \mathrm{dS} \mathrm{m}^{-1}\right)$ and IT1S2 $\left(2.00 \mathrm{dS} \mathrm{m}^{-1}\right)$. Treatments that were irrigated with $1.0 \mathrm{dS} \mathrm{m}^{-1}$ did not see as much of a drastic increase in their salinity levels; ICS1 $\left(1.68 \mathrm{dS} \mathrm{m}^{-1}\right)$, IT2S1 $\left(1.50 \mathrm{dS} \mathrm{m}^{-}\right.$ $\left.{ }^{1}\right)$, and IT1S1 $\left(1.19 \mathrm{dS} \mathrm{m}^{-1}\right)$. However, treatments that were irrigated with fresh water quality $\left(0.6 \mathrm{dS} \mathrm{m}^{-1}\right)$ saw very little change in salinity levels; IT2SC $\left(0.97 \mathrm{dS} \mathrm{m}^{-1}\right)$, ICSC $\left(0.94 \mathrm{dS} \mathrm{m}^{-1}\right)$, and IT1SC $\left(0.90 \mathrm{dS} \mathrm{m}^{-1}\right)$. A similar trend was seen in soil bulk EC, with the highest values found in both IT2S2 and ICS2 $\left(0.21 \mathrm{dS} \mathrm{m}^{-1}\right)$ followed by IT1S2 $(0.19$ $\mathrm{dS} \mathrm{m}{ }^{-1}$ ). Treatments irrigated with $0.6 \mathrm{dS} \mathrm{m}^{-1}$ had the lowest EC values, with the lowermost measurement seen in treatment IT2SC $\left(0.07 \mathrm{dS} \mathrm{m}^{-1}\right)$. Overall, beans that were inoculated with AMF and irrigated with the highest salinity had lower salinity in both soil bulk and pore water salinity during week 8 .

In general, pore water EC measurements were noticeably higher than soil bulk EC throughout the experiment. Pore water EC values ranged from 1.0 to $3.0 \mathrm{dS} \mathrm{m}^{-1}$ and soil bulk from 0.07 to $0.25 \mathrm{dS} \mathrm{m}{ }^{-1}$. A clear distinction is seen between the first half of the experiment (irrigated with fresh water quality) and second (irrigated with low quality water). The data showed that irrigating with low water quality influenced soil and pore 
water salinity. This impact was seen despite the short length of the experiment and relatively low salt-concentrations found in the irrigation water.

\subsection{Pore Water EC vs Soil Bulk EC Regression Line}

Figure 10 illustrates the linear regression between soil bulk and pore water EC amongst all treatments within the eight-week growth period. The dots represent the mean values for all nine treatments of both soil bulk and pore water EC in relation to each other. The results showed us that there was a positive linear relationship between the two variables with an $\mathrm{R}^{2}=0.5599$, with soil bulk EC increasing as pore water EC increases. Statistical analysis indicated that this relationship was significant with $\mathrm{p}<0.0001$.

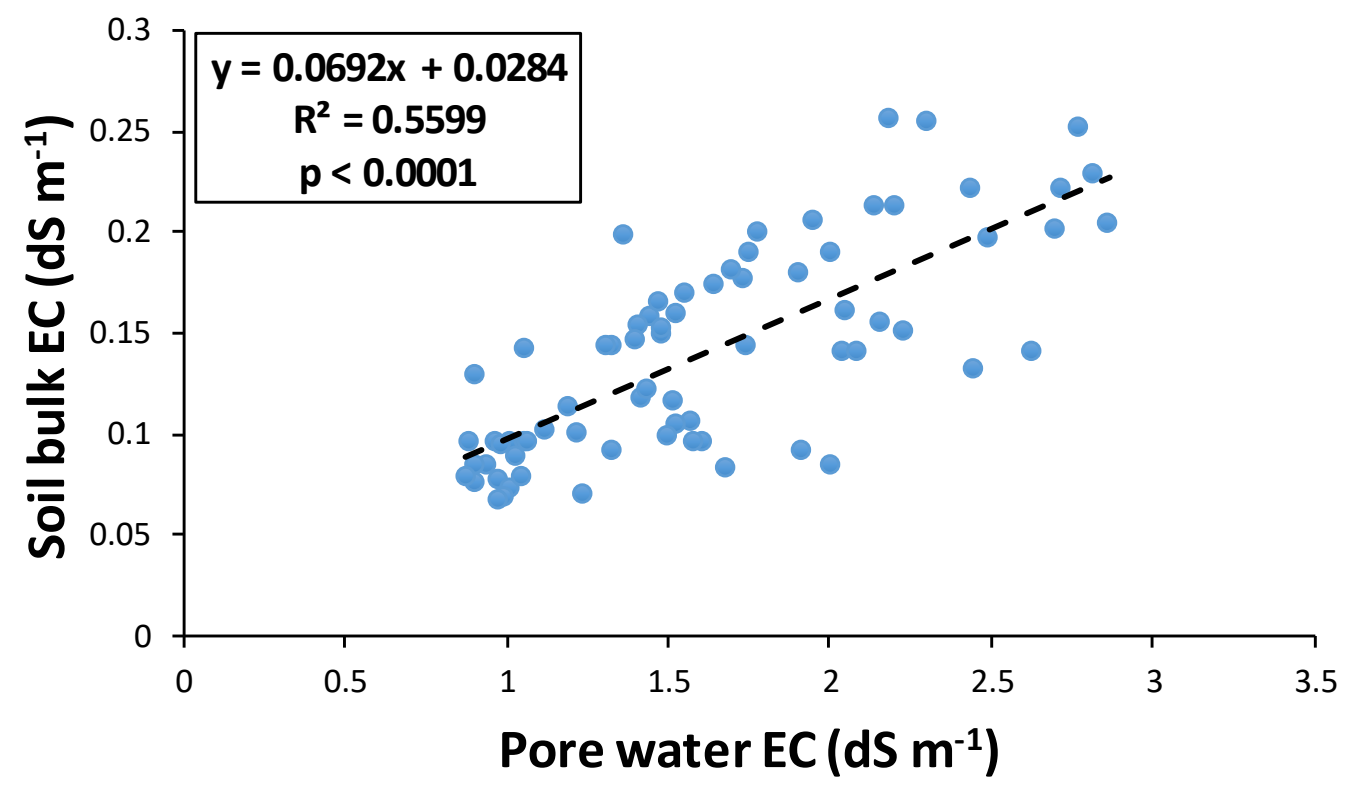

Figure 10 Linear regression analysis depicting soil bulk vs pore water electrical conductivity (EC) for all nine treatments. Treatments consist of inoculation type (IC $=$ No inoculation, IT1 $=$ Mycorrhizal, IT2 $=$ Rhizobium + Mycorrhizal $)$ and salinity levels $(\mathrm{SC}=$ Salinity control $0.6 \mathrm{dS} \mathrm{m}$ ${ }^{1} \mathrm{EC}, \mathrm{S} 1=1.0 \mathrm{dS} \mathrm{m}^{-1} \mathrm{EC}$, and $\mathrm{S} 2=2.0 \mathrm{dS} \mathrm{m}^{-1} \mathrm{EC}$ ). Values are expressed as mean and each treatment consisted of $n=10$. The dashed line represents a positive linear trend that's significant at $\mathrm{p}<0.05$. 


\subsection{Leaf Chlorophyll Concentration}

To evaluate the effect inoculation type and salinity levels had on leaf chlorophyll status, Soil Plant Analytical Development (SPAD) values were measured every two weeks during an eight-week growth period (Figure 11). Overall, mean SPAD values varied over time with the most noticeable differences observed during week 8 , which had seen four weeks of salinity treatment applications.

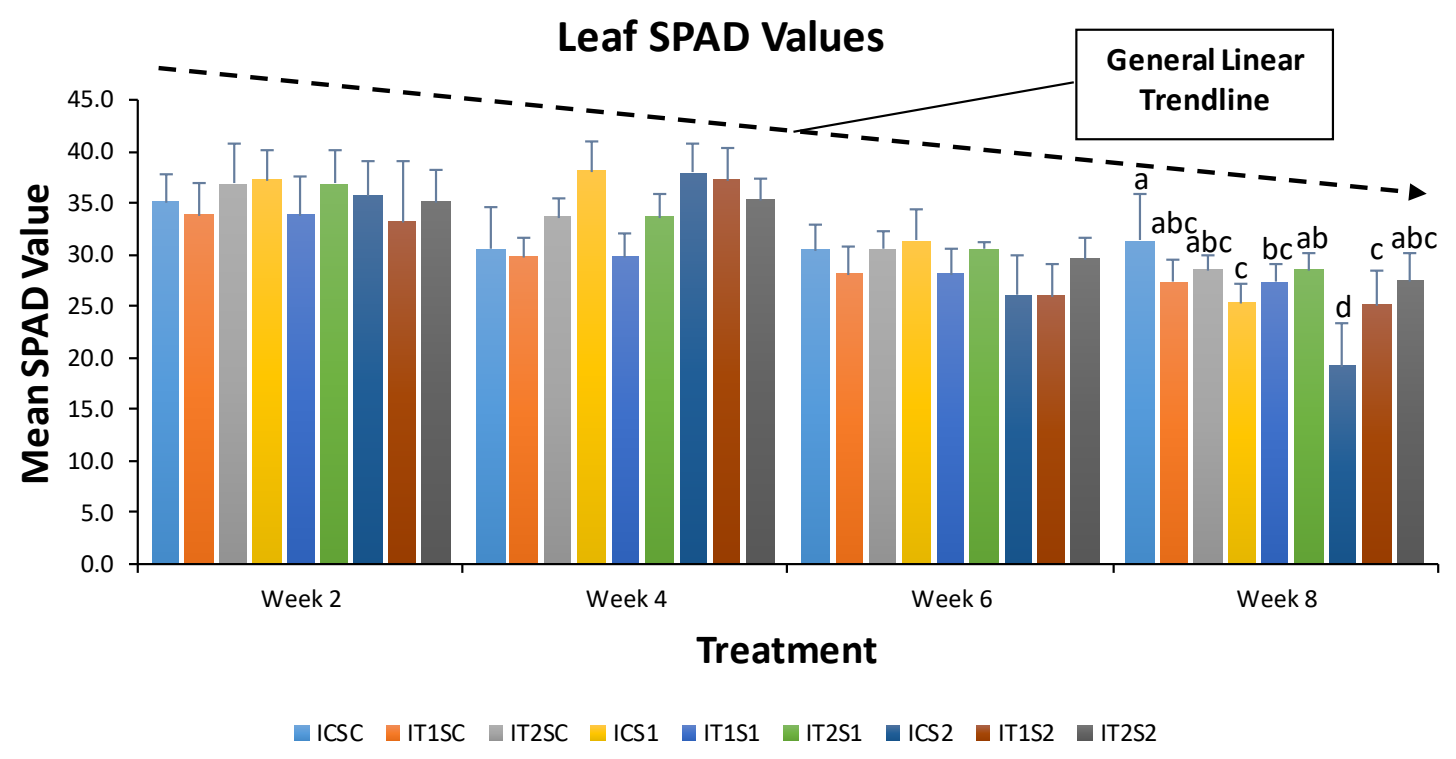

Figure 11 Graph depicting mean Soil Plant Analytical Development (SPAD) values for nine treatments (inoculation type $\mathrm{x}$ salinity level) on Caprice snap beans during weeks 2, 4, 6, and 8 of the growth period. Treatments consist of inoculation type $(\mathrm{IC}=$ No inoculation, IT1 $=$ Mycorrhizal, IT2 $=$ Rhizobium + Mycorrhizal $)$ and salinity levels $(\mathrm{SC}=$ Salinity control $0.6 \mathrm{dS} \mathrm{m}$ ${ }^{1} \mathrm{EC}, \mathrm{S} 1=1.0 \mathrm{dS} \mathrm{m}^{-1} \mathrm{EC}$, and $\mathrm{S} 2=2.0 \mathrm{dS} \mathrm{m}^{-1} \mathrm{EC}$ ). Values are expressed as mean + Standard Deviation error bars. Each treatment consisted of $n=10$. Two-way ANOVA was performed on all nine treatments during week 8 . Means within a column followed by the same letter are not significantly different at $\mathrm{P}<0.05$.

Statistical analysis for week 8 revealed inoculation type had no significant effect on values when beans were grown in non-stressed conditions $\left(\mathrm{SC}=0.06 \mathrm{dS} \mathrm{m}^{-1}\right)$. The 
greatest value during this time was observed in treatment ICSC (31.34), followed by IT2SC and IT2S1, both of which had similar values (28.47). Out of the three treatments in non-stressed conditions (ICSC, IT1SC, and IT2SC), beans with no inoculation (IC) showed the greatest mean value with IT2SC (28.47) and IT1SC (27.36) following closely behind.

When irrigated with their threshold salinity EC $\left(\mathrm{S} 1=1.0 \mathrm{dS} \mathrm{m} \mathrm{m}^{-1}\right)$, beans with no inoculation (ICS1) saw a significant decrease in SPAD value when compared to noninoculated beans in non-stressed conditions (ICSC). Beans with AMF inoculation (IT1S1) saw no significant difference under similar stress conditions. However, when dual inoculated with Rhizobium (IT2S1), a significant increase in SPAD value (28.47) was observed.

The lowermost mean SPAD value (19.15) was observed in ICS2, where noninoculated beans were irrigated with the highest experimental salinity level $(\mathrm{S} 2=2.0 \mathrm{dS}$ $\left.\mathrm{m}^{-1} \mathrm{EC}\right)$. On the other hand, treatments grown under the same salinity level had values that were positively affected by inoculation. Inoculating salt-stressed beans with AMF (IT1) as well as AMF and Rhizobium (IT2) led to significantly higher SPAD values, with IT1S2 (25.17) and IT2S2 (27.51) respectively. Overall, treatments ICSC, ICS1 (25.38), and ICS2 were all significantly different.

Our results revealed that irrigating salt-sensitive crops with low water quality had a negative impact on leaf chlorophyll concentrations despite the relatively short salinity treatment applications and intensity levels. Leaf chlorophyll concentration reductions were observed at the bean's salinity threshold (1.0 EC) and to a greater extent at higher 
levels (2.0 EC). At the threshold level, beans dual inoculated with AMF and Rhizobium significantly outperformed beans with no inoculation or only AMF inoculation. At higher salinity levels, both types of inoculation aided in mitigating salt stress effects on leaf chlorophyll concentration reductions.

4.5 Root arbuscular mycorrhizal percent infection, soil moisture, and soil $\mathrm{pH}$

The percent AMF colonization in snap bean roots is shown in table 3. Arbuscular mycorrhizal colonization within the roots depended greatly on the presence of inoculation. This was seen in beans grown in non-stressed conditions (IC) as well as those subjected to salt-stress (IT1 and IT2). The highest AM colonization percentages were observed in IT1SC (73\%), IT2SC (72\%), and IT2S1 (71\%) while the lowermost percentages were seen in ICS1 (1\%), ICSC (3\%), and ICS2 (13\%). Overall, the presence of AMF alone or with Rhizobium significantly increased the AM colonization percentages on snap bean roots across all salinity levels $\left(0.6,1.0\right.$, and $\left.2.0 \mathrm{ds} \mathrm{m}^{-1}\right)$. However, there was no significant difference seen in-between inoculation treatments consisting solely of AMF (T1) or AMF/Rhizobium (T2) in non-stressed and salt-stressed conditions.

The soil moisture content for all nine treatments was calculated post-harvest. Treatments ICSC (310.5\%), ICS2 (307.9\%), and IT1S2 (306.8\%) had the greatest percentages while the lowest were IT2SC (256.7\%), IT2S1 (263.4\%), and IT2S2 (266.7\%). Overall, salinity did not have a significant effect on soil moisture content. However, co-inoculation of snap beans with AMF and Rhizobium in non-stressed 
conditions seemed to significantly influence soil moisture content and reducing water availability.

Table 3 Effect of salinity level and inoculation type on soil and root properties.

\begin{tabular}{|c|c|c|c|c|c|}
\hline \multirow[t]{2}{*}{ Treatment } & \multirow{2}{*}{$\begin{array}{c}\text { Root AM } \\
\text { colonization } \\
\text { percent } \\
\text { infection } \\
(\%) \\
\end{array}$} & \multirow{2}{*}{$\begin{array}{c}\text { Soil Moisture } \\
\text { Content } \\
(\%)\end{array}$} & \multicolumn{3}{|c|}{ Soil pH } \\
\hline & & & Week 1 & Week 4 & Week 8 \\
\hline ICSC & $3.0^{\mathrm{cd}} \pm 4.5$ & $310.5^{\mathrm{a}} \pm 5.4$ & $6.26 \pm 0.46$ & $6.24 \pm 0.33$ & $6.63 \pm 0.48$ \\
\hline IT1SC & $73.0^{\mathrm{a}} \pm 14.8$ & $288.9^{\mathrm{ab}} \pm 24.8$ & $6.66 \pm 0.31$ & $6.50 \pm 0.27$ & $6.52 \pm 0.32$ \\
\hline IT2SC & $72.0^{\mathrm{a}} \pm 29.5$ & $256.7^{b} \pm 21.3$ & $6.48 \pm 0.24$ & $6.45 \pm 0.20$ & $6.76 \pm 0.22$ \\
\hline ICS 1 & $1.0^{\mathrm{d}} \pm 2.2$ & $292.2^{\mathrm{ab}} \pm 15.8$ & $6.40 \pm 0.25$ & $6.46 \pm 0.30$ & $6.36 \pm 0.38$ \\
\hline IT1S1 & $42.0^{\mathrm{abc}} \pm 31.5$ & $279.3^{\mathrm{ab}} \pm 32.0$ & $6.56 \pm 0.54$ & $6.06 \pm 0.43$ & $6.30 \pm 0.34$ \\
\hline IT2S 1 & $71.0^{\mathrm{a}} \pm 4.2$ & $263.4^{\mathrm{ab}} \pm 46.7$ & $6.52 \pm 0.44$ & $6.34 \pm 0.26$ & $6.60 \pm 0.18$ \\
\hline ICS2 & $13.0^{\mathrm{bcd}} \pm 15.7$ & $307.9^{\mathrm{ab}} \pm 17.3$ & $6.68 \pm 0.26$ & $6.46 \pm 0.32$ & $6.77 \pm 0.37$ \\
\hline IT1S2 & $46.0^{\mathrm{ab}} \pm 14.7$ & $306.8^{\mathrm{ab}} \pm 21.4$ & $6.82 \pm 0.30$ & $6.42 \pm 0.27$ & $6.48 \pm 0.22$ \\
\hline IT2S2 & $53.0^{\mathrm{a}} \pm 24.9$ & $266.7^{\mathrm{ab}} \pm 21.9$ & $6.51 \pm 0.32$ & $6.34 \pm 0.26$ & $6.60 \pm 0.30$ \\
\hline
\end{tabular}

Treatments consist of inoculation type (IC = No inoculation, IT1 = Mycorrhizal, IT2 = Rhizobium + Mycorrhizal) and salinity levels ( $\mathrm{SC}=$ Salinity control $0.6 \mathrm{dS} \mathrm{m}^{-1} \mathrm{EC}, \mathrm{S} 1=1.0 \mathrm{dS} \mathrm{m}^{-1} \mathrm{EC}$, and $\left.\mathrm{S} 2=2.0 \mathrm{dS} \mathrm{m}^{-1} \mathrm{EC}\right)$. Values are expressed as mean \pm Standard Deviation. Each treatment consisted of $n=10$ (Root AM Colonization Percent Infection, Soil Moisture Content) and $n=10$ (Soil $\mathrm{pH}$ ). Two-way ANOVA was performed on Root AM colonization \% and soil moisture content. Means within a column followed by the same letter are not significantly different at $\mathrm{P}<$ 0.05 .

Further soil analysis consisted of taking periodic soil $\mathrm{pH}$ measurements during weeks 1,4 , and 8 of the growth period as well as calculating the stable aggregate content post-harvest. The greatest and lowest soil $\mathrm{pH}$ measurements for these periods were; week 1 IT1S2 (6.82) and ICSC (6.26), week 2 IT1SC (6.50) and IT1S1 (6.06), and week 3 
ICS2 (6.77) and IT1S1 (6.30). After running tests for soil aggregate content (data not shown) it has been determined that the data will remain inconclusive. This is due to the nature of the potting soil used, which consisted mainly of organic material such as Canadian sphagnum peat moss and bark. The high concentration of organic matter and little mineral content made this particular soil analysis led to skewed results, as the majority of aggregates were made of organic matter and not soil particles.

\subsection{Visual Observations}

Prior to termination, salt stress effects on all nine treatments were observed during weeks four and seven of the growth period. One of the main salt stress effects identified was chlorosis (Figure 12.c), which involves the yellow coloring of the leaves caused by a lack of chlorophyll concentration (Freidenreich et al., 2019). The main other stress identified was the firing of the leaf margins (Figure 12.d), which occurs when the leaf edge decays and darkens over time.

During week four, chlorosis was not commonly found across all nine treatments. The majority of leaves were relatively green and vibrant in color, similar to the coloration found in figure 12.a. The lack of yellowing at this point in time is due to the lack of salinity treatment applications, which only commenced four weeks into the growth period. However, once salinity treatments had time to take effect, there was stark difference in the coloring of the leaves observed during week seven for treatments who were irrigated with greater EC levels. Visually, the majority of S2 treatments $\left(2.0 \mathrm{dS} \mathrm{m}^{-1}\right)$ snap bean leaves were categorized as moderate or severe in terms of chlorosis. Salinity 1 (S1) treatments were irrigated with moderate EC levels $\left(1.0 \mathrm{dS} \mathrm{m}^{-1}\right)$ and had chlorosis in 
the leaves that ranged from minor to severe. Salinity control (SC) treatments were the least visually affected, with leaves ranging from almost no impact to minor chlorosis effects (Figure 12.b). Firing of the leaf margins were mainly found in S1 and S2 treatments.
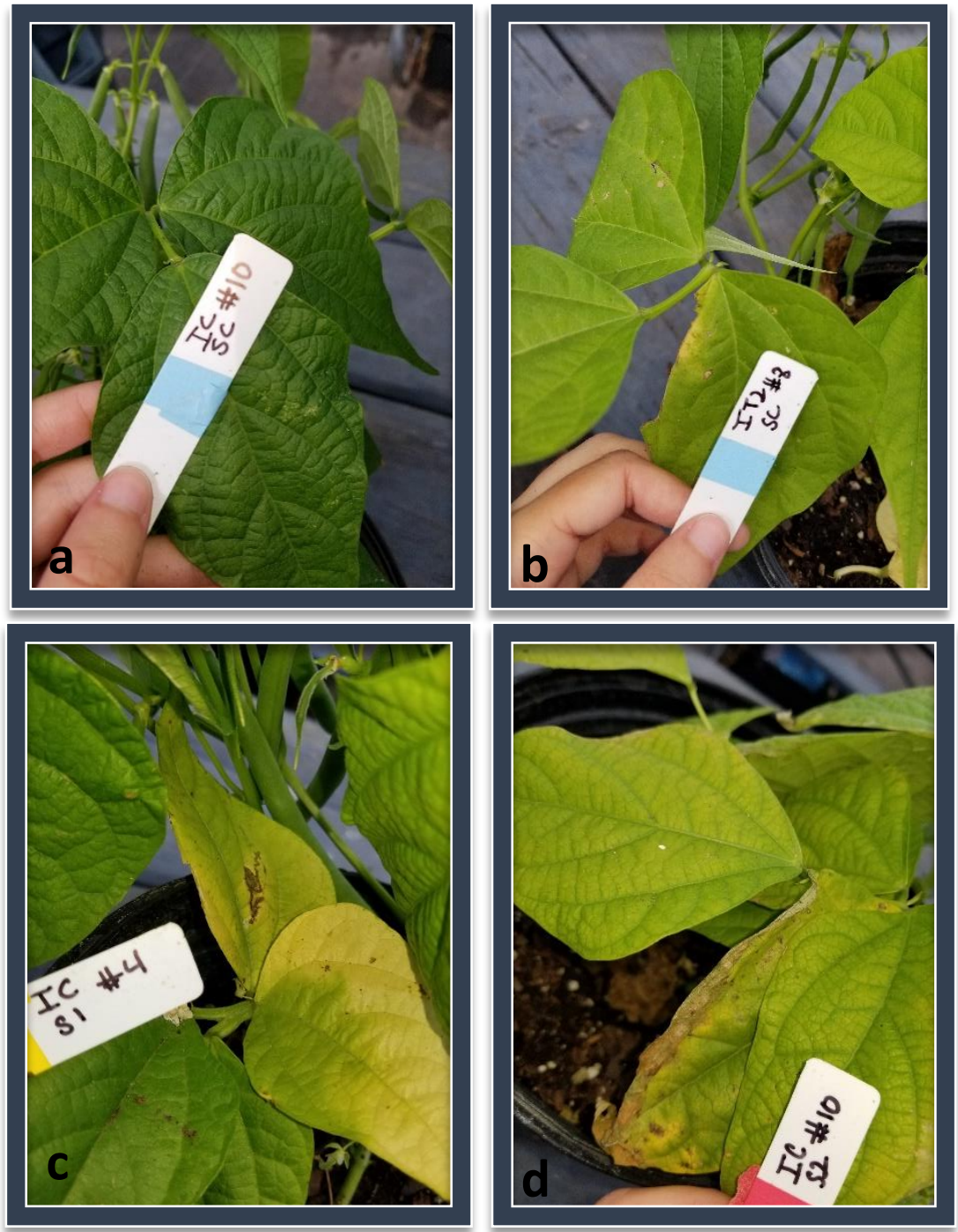

Figure 12 Visual representation of varying salinity effects on snap bean leaves prior to termination; a) no impact, b) minor chlorosis effects on edges of leaves for non-stressed ( $0.6 \mathrm{dS}$ $\left.\mathrm{m}^{-1}\right)$ co-inoculated beans, c) moderate chlorosis on salt-stressed $\left(1.0 \mathrm{dS} \mathrm{m} \mathrm{m}^{-1}\right)$ non-inoculated snap beans, and d) firing of the leaf margins on highly stressed $\left(2.0 \mathrm{dS} \mathrm{m}^{-1}\right)$ non-inoculated beans. 
Further distinctions were seen during week seven when comparing inoculant treatments. While there was no visual difference identified in SC treatments irrigated with non-saline water $\left(0.6 \mathrm{ds} \mathrm{m}^{-1}\right)$, snap beans that were inoculated either with AMF (IT1) or AMF/Rhizobium (IT2) had greener leaves than non-inoculated beans (IC) in S1 treatments. Similarly, this visual distinction was seen in S2 treatments. These observations have a positive correlation with the leaf chlorophyll concentrations measured in this experiment (Figure 11). Overall observations indicate that relatively low salinity (1.0 and $2.0 \mathrm{dS} \mathrm{m}^{-1}$ ) can still stress snap beans, resulting in lower leaf chlorophyll concentrations and noticeable chlorosis. However, co-inoculation with AMF and Rhizobium aided in alleviating the yellowing of the leaves to a certain degree.

\subsection{Glomalin Content}

Two main glomalin fractions were extracted and measured from dry soil samples taken after snap bean termination. Figure 13 depicts the measurement of easily extractable glomalin-related soil protein and total glomalin-related soil protein in $\mathrm{mg} \mathrm{g}^{-1}$ of dry soil. Numerically, there was not a very distinct difference in measurements for EEG (Figure 13.a), with the highest values measured from ICS1 (12.80 $\left.\mathrm{mg} \mathrm{g}^{-1}\right)$, ICSC (12.69 $\left.\mathrm{mg} \mathrm{g}^{-1}\right)$, and IT1S2 (12.04 $\left.\mathrm{mg} \mathrm{g}^{-1}\right)$. The lowest EEG values were IT2SC (10.10 mg $\left.\mathrm{g}^{-1}\right)$ and IT2S2 $\left(10.39 \mathrm{mg} \mathrm{g}^{-1}\right)$. In both SC $\left(0.6 \mathrm{dS} \mathrm{m}^{-1}\right)$ and $\mathrm{S} 1\left(1.0 \mathrm{dS} \mathrm{m}^{-1}\right)$ treatments, AMF (IT1) and AMF/Rhizobium (IT2) inoculation resulted in lower EEG concentrations when compared to non-inoculated (IC) treatments. In all three salinity treatments, coinoculation resulted in lower EEG production than treatments inoculated with AMF only. The only numerical difference from this trend was located in treatments with S2 (2.0 dS 
$\mathrm{m}^{-1}$ ) salinity treatments, as AMF inoculation resulted in greater EEG production $($ IT1S2 $=$ $12.04 \mathrm{mg} \mathrm{g}^{-1}$ ) than its corresponding non-inoculated (ICS2 $=11.18 \mathrm{mg} \mathrm{g}^{-1}$ ) and coinoculated $\left(\mathrm{IT} 2 \mathrm{~S} 2=10.34 \mathrm{mg} \mathrm{g}^{-1}\right)$ treatments.

Figure 13.b depicts the total glomalin-related soil protein (TG) measurements taken for all nine treatments. The highest TG values measured were from treatments IT1S2 (206.13 $\left.\mathrm{mg} \mathrm{g}^{-1}\right)$, ICS2 (198.67 $\left.\mathrm{mg} \mathrm{g}^{-1}\right)$, and ICS1 (198.37 $\left.\mathrm{mg} \mathrm{g}^{-1}\right)$ while the lowest concentration values were measured from IT2SC (155.76 $\left.\mathrm{mg} \mathrm{g}^{-1}\right)$ and IT1SC (169.13 mg $\left.\mathrm{g}^{-1}\right)$. A similar trend was seen between EEG and TG across all three salinity levels despite TG concentrations being greater in comparison. In both SC and S1, TG concentrations was measured to be greater in soils from non-inoculated snap beans than those with AMF inoculation or AMF/Rhizobium co-inoculation. Additionally, singular AMF inoculation at S2 salinity treatment resulted in greater TG production than either non-inoculated or coinoculated snap beans. 


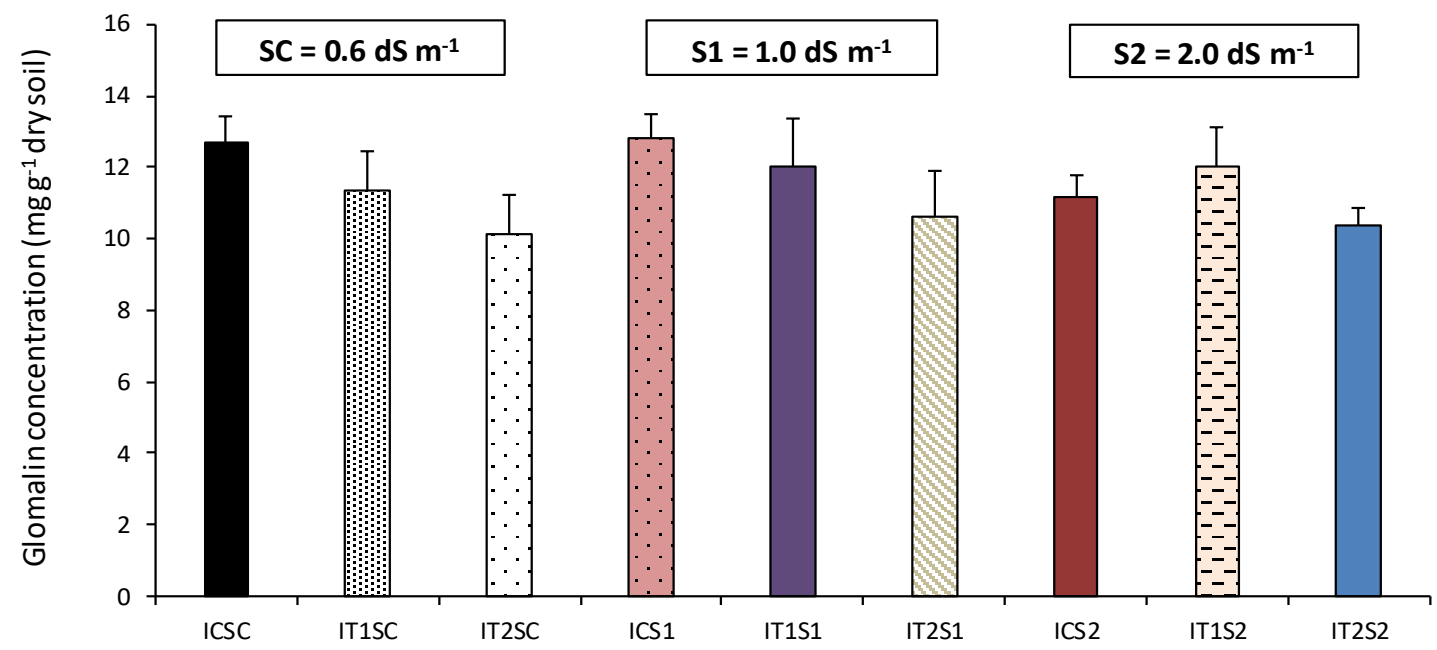

b Total Glomalin-related Soil Protein (TG)

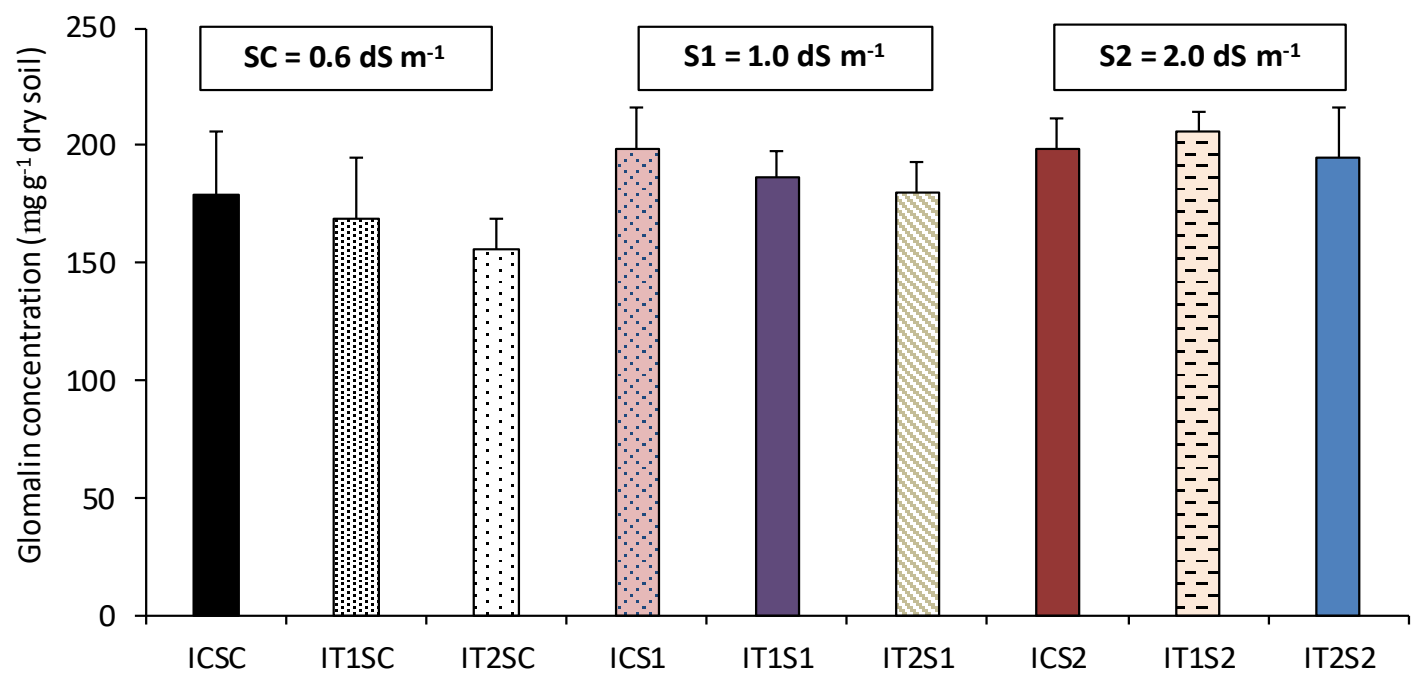

Figure 13 Graph depicting mean a) Easily Extractable Glomalin-related Soil Protein (EEG) and b) Total Glomalin-related Soil Protein (TG) per $\mathrm{mg} \mathrm{g}^{-1}$ of dry soil for all nine treatments. (inoculation type $\mathrm{x}$ salinity level) on Caprice snap beans. Treatments consist of inoculation type (IC = No inoculation, IT1 $=$ Mycorrhizal, IT2 $=$ Rhizobium + Mycorrhizal $)$ and salinity levels (SC $=$ Salinity control $0.6 \mathrm{dS} \mathrm{m}^{-1} \mathrm{EC}, \mathrm{S} 1=1.0 \mathrm{dS} \mathrm{m}^{-1} \mathrm{EC}$, and S2 $=2.0 \mathrm{dS} \mathrm{m}^{-1} \mathrm{EC}$ ). The graph is expressed as mean + Standard Deviation error bars. Each treatment consisted of $n=5$.

Overall, conditions in which there was low or no salinity stress resulted in greater EEG and TG concentrations from soils with non-inoculated snap beans. This contradicted 
our second and third hypotheses, which speculated co-inoculation of AMF and Rhizobium would result in greater glomalin production due to the growth potential of a tripartite symbiotic relationship. Instead, co-inoculation measurements were the lowest across all three salinity levels when compared to their respective inoculation treatments. A potential reason as to why EEG and TG concentrations from soils with non-inoculated snap beans were higher may be due to the method of EEG and TG extraction in itself. Currently, it is difficult extract glomalin measurements that contain solely glomalin as the methods could result in measuring lipids, humic materials, and other heat-stable proteins, some of which aren't secreted by the hyphae of AMF (Gillespie et al., 2011; Whiffen et al., 2007). This could explain why some of the inoculant controls were somewhat higher than treatments which contained AMF. Additionally, while GRSP measurements didn’t differ greatly numerically, there was a small trend found in which EEG/TG concentration increased as salinity levels increased for treatments with AMF inoculation. This was supported in previous literature where GRSP concentrations increased with rising salinity levels (Hammer \& Rillig, 2011).

\section{CONCLUSION}

The results of this study indicate that the tripartite symbiotic relationship between the host plant snap bean, arbuscular mycorrhizal fungi, and Rhizobium exists to a certain degree when under salinity stress. This synergetic effect was mainly seen in alleviating the chlorosis effect observed in the leaves of stressed plants by mitigating reductions to leaf chlorophyll concentrations. These results also suggest that dual inoculation significantly increased nitrogen uptake for snap beans under salinity stress. Additionally, 
co-inoculation had a minor inhibitory effect on GRSP production regardless of salinity treatment.

Other plant growth factors such as plant height, biomass, and yield were not as affected by salinity or inoculation. This lack of impact may be due to the short duration of the experiment, as snap beans were only irrigated with salinity treatments for four weeks. During this time, the impact of salt stress may not have been as detrimental to the snap beans as they could have been had the growth period been longer.

Rising global temperatures, sea level rise, and salinization continue to threaten agricultural communities as a whole. However, agriculture communities located nearby and supplied by coastal freshwater aquifers such as Southeastern Florida have an increased risk of freshwater contamination due to salt-water intrusion. Salt-sensitive crops may be the first of many to be impacted should risks to groundwater contamination continue to rise. Because of this, it is crucial to find sustainable and cost-effective ways in which salt stress effects can be alleviated so as to not see reductions in crop productivity and yield. The findings within this study will help to expand knowledge on inoculation practices aiming to improve agricultural sustainability as well as snap bean salt tolerance. 


\section{REFERENCES}

Al-garni, S. M. S. (2006). Increased heavy metal tolerance of cowpea plants by dual inoculation of an arbuscular mycorrhizal fungi and nitrogen-fixer Rhizobium bacterium. African Journal of Biotechnology, 5(2), 133-142.

Al-Karaki, G., \& Al-Raddad, A. (1997). Effects of arbuscular mycorrhizal fungi and drought stress on growth and nutrient uptake of two wheat genotypes differing in drought resistance. Mycorrhiza, 7(2), 83-88. https://doi.org/10.1007/s005720050166

Ashrafi, E., Zahedi, M., \& Razmjoo, J. (2014). Co-inoculations of arbuscular mycorrhizal fungi and rhizobia under salinity in alfalfa. Soil Science and Plant Nutrition, 60(5), 619-629. https://doi.org/10.1080/00380768.2014.936037

Assefa, T., Assibi Mahama, A., Brown, A. V., Cannon, E. K. S., Rubyogo, J. C., Rao, I. M., ... Cannon, S. B. (2019). A review of breeding objectives, genomic resources, and marker-assisted methods in common bean (Phaseolus vulgaris L.). Molecular Breeding, 39(2). https://doi.org/10.1007/s11032-018-0920-0

Atieno, M., \& Lesueur, D. (2019). Opportunities for improved legume inoculants: enhanced stress tolerance of rhizobia and benefits to agroecosystems. Symbiosis, 77(3), 191-205. https://doi.org/10.1007/s13199-018-0585-9

Barlow, P. M., \& Reichard, E. G. (2010). Saltwater intrusion in coastal regions of North America. Hydrogeology Journal, 18(1), 247-260. https://doi.org/10.1007/s10040009-0514-3

Bedini, S., Pellegrino, E., Avio, L., Pellegrini, S., Bazzoffi, P., Argese, E., \& Giovannetti, M. (2009). Changes in soil aggregation and glomalin-related soil protein content as affected by the arbuscular mycorrhizal fungal species Glomus mosseae and Glomus intraradices. Soil Biology and Biochemistry, 41(7), 1491-1496.

https://doi.org/10.1016/j.soilbio.2009.04.005

Bernardo et al 2019 - Metabolic responses triggered by arbuscular mycorrhiza enhance tolerance to water stress in wheat cultivars. (n.d.).

Borkowska, B. (2002). Growth and photosynthetic activity of micropropagated strawberry plants inoculated with endomycorrhizal fungi (AMF) and growing under drought stress. Acta Physiologiae Plantarum, 24(4), 365-370. https://doi.org/10.1007/s11738-002-0031-7

Bothe, H. (2012). Arbuscular mycorrhiza and salt tolerance of plants. Symbiosis, 58(1-3), 7-16. https://doi.org/10.1007/s13199-012-0196-9

Bureau of Economic and Business Research (BEBR). 2019. Projections of Florida Population by County, 2020-2045, with Estimates for 2018. Retrieved from https://www.bebr.ufl.edu/sites/default/files/Research\%20Reports/projections_2019.p df 
Chalk, P. M., Souza, R. D. F., Urquiaga, S., Alves, B. J. R., \& Boddey, R. M. (2006). The role of arbuscular mycorrhiza in legume symbiotic performance. Soil Biology and Biochemistry, 38(9), 2944-2951. https://doi.org/10.1016/j.soilbio.2006.05.005

Deaker, R., Roughley, R. J., \& Kennedy, I. R. (2004). Legume seed inoculation technology - A review. Soil Biology and Biochemistry, 36(8), 1275-1288. https://doi.org/10.1016/j.soilbio.2004.04.009

Diouf, D., Duponnois, R., Ba, A. T., Neyra, M., \& Lesueur, D. (2005). Symbiosis of Acacia auriculiformis and Acacia mangium with mycorrhizal fungi and Bradyrhizobium spp. improves salt tolerance in greenhouse conditions. Functional Plant Biology, 32(12), 1143-1152. https://doi.org/10.1071/FP04069

Evelin, H., Devi, T. S., Gupta, S., \& Kapoor, R. (2019). Mitigation of Salinity Stress in Plants by Arbuscular Mycorrhizal Symbiosis: Current Understanding and New Challenges. Frontiers in Plant Science, 10(April). https://doi.org/10.3389/fpls.2019.00470

Evelin, H., Kapoor, R., \& Giri, B. (2009). Arbuscular mycorrhizal fungi in alleviation of salt stress: A review. Annals of Botany, 104(7), 1263-1280. https://doi.org/10.1093/aob/mcp251

FAO. (2015). Intergovernmental Technical Panel on Soils. Status of the World's Soil Resources. Retrieved from http://www.fao.org/3/i5199e/I5199E.pdf\%0Ahttp://www.fao.org/3/a-i5199e.pdf

Ferguson, G., \& Gleeson, T. (2012). Vulnerability of coastal aquifers to groundwater use and climate change. Nature Climate Change, 2(5), 342-345. https://doi.org/10.1038/nclimate1413

Franzini, V. I., Azcón, R., Ruiz-Lozano, J. M., \& Aroca, R. (2019). Rhizobial symbiosis modifies root hydraulic properties in bean plants under non-stressed and salinitystressed conditions. Planta, 249(4), 1207-1215. https://doi.org/10.1007/s00425-01803076-0

Freidenreich, A., Barraza, G., Jayachandran, K., \& Khoddamzadeh, A. A. (2019). Precision Agriculture Application for Sustainable Nitrogen Management of Justicia brandegeana Using Optical Sensor Technology. Agriculture, 9(5), 98. https://doi.org/10.3390/agriculture9050098

Gao, W. Q., Wang, P., \& Wu, Q. S. (2019). Functions and application of glomalin-related soil proteins: A review. Sains Malaysiana, 48(1), 111-119. https://doi.org/10.17576/jsm-2019-4801-13

Gillespie, A. W., Farrell, R. E., Walley, F. L., Ross, A. R. S., Leinweber, P., Eckhardt, K. U., ... Blyth, R. I. R. (2011). Glomalin-related soil protein contains nonmycorrhizal-related heat-stable proteins, lipids and humic materials. Soil Biology and Biochemistry. https://doi.org/10.1016/j.soilbio.2010.12.010 
Gleick, P. H. (2003). Water Use. Annual Review of Environment and Resources, 28(1), 275-314. https://doi.org/10.1146/annurev.energy.28.040202.122849

Gloser, V., Zwieniecki, M. A., Orians, C. M., \& Holbrook, N. M. (2007). Dynamic changes in root hydraulic properties in response to nitrate availability. Journal of Experimental Botany, 58(10), 2409-2415. https://doi.org/10.1093/jxb/erm118

Gopalakrishnan, S., Sathya, A., Vijayabharathi, R., Varshney, R. K., Gowda, C. L. L., \& Krishnamurthy, L. (2015). Plant growth promoting rhizobia: challenges and opportunities. 3 Biotech, 5(4), 355-377. https://doi.org/10.1007/s13205-014-0241-x

Grümberg, B. C., Urcelay, C., Shroeder, M. A., Vargas-Gil, S., \& Luna, C. M. (2015). The role of inoculum identity in drought stress mitigation by arbuscular mycorrhizal fungi in soybean. Biology and Fertility of Soils, 51(1), 1-10. https://doi.org/10.1007/s00374-014-0942-7

Hack, C. M., Porta, M., Schäufele, R., \& Grimoldi, A. A. (2019). Arbuscular mycorrhiza mediated effects on growth, mineral nutrition and biological nitrogen fixation of Melilotus alba Med. in a subtropical grassland soil. Applied Soil Ecology, 134, 3844. https://doi.org/https://doi.org/10.1016/j.apsoil.2018.10.008

Hamaoui, B., Abbadi, J., Burdman, S., Rashid, A., \& Sarig, S. (2001). Effects of inoculation with Azospirillum brasilense on chickpeas ( Cicer arietinum ) and faba beans ( Vicia faba ) under different growth conditions Agronomie, 21, 553-560. https://doi.org/10.1051/agro:2001144

Hammer, E. C., \& Rillig, M. C. (2011). The influence of different stresses on glomalin levels in an arbuscular mycorrhizal fungus-salinity increases glomalin content. PLoS ONE, 6(12), 1-5. https://doi.org/10.1371/journal.pone.0028426

Hodge, A. (2000). Microbial ecology of the arbuscular mycorrhiza. FEMS Microbiology Ecology, 32(2), 91-96. https://doi.org/10.1016/S0168-6496(00)00023-4

Jeffries, P., Gianinazzi, S., Perotto, S., Turnau, K., \& Barea, J. M. (2003). The contribution of arbuscular mycorrhizal fungi in sustainable maintenance of plant health and soil fertility. Biology and Fertility of Soils, 37(1), 1-16. https://doi.org/10.1007/s00374-002-0546-5

Juniper, S., \& Abbott, L. (1993). Vesicular-arbuscular mycorrhizas and soil salinity. Mycorrhiza, 4(2), 45-57. https://doi.org/10.1007/BF00204058

Kala Christi Bai 2011 - Effect of rhizobium inoculation on the growth and yield of horsegram dolichos biflorus linn.pdf. (n.d.).

Kaleris, V. K., \& Ziogas, A. I. (2013). The effect of cutoff walls on saltwater intrusion and groundwater extraction in coastal aquifers. Journal of Hydrology. https://doi.org/10.1016/j.jhydrol.2012.11.007

Lal, R. (2003). Soil erosion and the global carbon budget. Environment International, 29(4), 437-450. https://doi.org/https://doi.org/10.1016/S0160-4120(02)00192-7 
Langevin, C. D., \& Zygnerski, M. (2013). Effect of sea-level rise on salt water intrusion near a coastal well field in Southeastern Florida. Groundwater, 51(5), 781-803. https://doi.org/10.1111/j.1745-6584.2012.01008.x

Latef, A. A. H. A., Hashem, A., Rasool, S., Abd-Allah, E. F., Alqarawi, A. A., Egamberdieva, D., ... Ahmad, P. (2016). Arbuscular mycorrhizal symbiosis and abiotic stress in plants: A review. Journal of Plant Biology, 59(5), 407-426. https://doi.org/10.1007/s12374-016-0237-7

Lichtfouse, E. (2009). Climate Change, Intercropping, Pest Control and Beneficial Microorganisms: Sustainable Agriculture Reviews 2.

Ling, Q., Huang, W., \& Jarvis, P. (2011). Use of a SPAD-502 meter to measure leaf chlorophyll concentration in Arabidopsis thaliana. Photosynthesis Research, 107(2), 209-214. https://doi.org/10.1007/s11120-010-9606-0

Manchanda, G., \& Garg, N. (2008). Salinity and its effects on the functional biology of legumes. Acta Physiologiae Plantarum, 30(5), 595-618. https://doi.org/10.1007/s11738-008-0173-3

Marella, R. L. (2012). Water Withdrawals in Florida, 2012, 10. Retrieved from http://www.visitflorida.com/en-us/media/

Mathur, S., Tomar, R. S., \& Jajoo, A. (2019). Arbuscular Mycorrhizal fungi (AMF) protects photosynthetic apparatus of wheat under drought stress. Photosynthesis Research, 139(1-3), 227-238. https://doi.org/10.1007/s11120-018-0538-4

Mcgonigle, T. P. et al. (1990). A new method which gives an objetive measure of colonisation of roots by vesicular.pdf. New Phytol, (115), 495-501.

McGuiness, P. N., Reid, J. B., \& Foo, E. (2019). The Role of Gibberellins and Brassinosteroids in Nodulation and Arbuscular Mycorrhizal Associations. Frontiers in Plant Science, 10(March). https://doi.org/10.3389/fpls.2019.00269

Munns, R., \& Tester, M. (2008). Mechanisms of Salinity Tolerance. Annual Review of Plant Biology, 59(1), 651-681. https://doi.org/10.1146/annurev.arplant.59.032607.092911

Numan, M., Bashir, S., Khan, Y., Mumtaz, R., Shinwari, Z. K., Khan, A. L., ... ALHarrasi, A. (2018). Plant growth promoting bacteria as an alternative strategy for salt tolerance in plants: A review. Microbiological Research, 209(February), 21-32. https://doi.org/10.1016/j.micres.2018.02.003

Patton, J. J., Burras, L., Konen, M. E., \& Molstad, N. E. (2001). An Accurate and Inexpensive Apparatus and Method for Teaching and Measuring Stable Aggregate Content of Soils, 30, 84-88. 
Peoples, M. B.Brockwell, J.Herridge, D. F.Rochester, I. J., Alves, B. J. R., Urquiaga, S., Boddey, R. M., Dakora, F. D., Bhattarai, S., ... Jensen, E. S. (2009). The contributions of nitrogen-fixing crop legumes to the productivity of agricultural systems. Symbiosis, 48(1-3), 1-17. https://doi.org/10.1007/BF03179980

Pitman, M. G., \& Läuchli, A. (2002). Global Impact of Salinity and Agricultural Ecosystems. Salinity: Environment - Plants - Molecules, 3-20. https://doi.org/10.1007/0-306-48155-3_1

Ramos, T. B., Darouich, H., Šimůnek, J., Gonçalves, M. C., \& Martins, J. C. (2019). Soil salinization in very high-density olive orchards grown in southern Portugal: Current risks and possible trends. Agricultural Water Management, 217(February), 265-281. https://doi.org/10.1016/j.agwat.2019.02.047

Ren, C. G., Bai, Y. J., Kong, C. C., Bian, B., \& Xie, Z. H. (2016). Synergistic Interactions Between Salt-tolerant Rhizobia and Arbuscular Mycorrhizal Fungi on Salinity Tolerance of Sesbania cannabina Plants. Journal of Plant Growth Regulation, 35(4), 1098-1107. https://doi.org/10.1007/s00344-016-9607-0

Rengasamy, P. (2002). Transient salinity and subsoil constraints to dryland farming in Australian sodic soils: An overview. In Australian Journal of Experimental Agriculture. https://doi.org/10.1071/EA01111

Rillig, M. C. (2004). Arbuscular mycorrhizae, glomalin, and soil aggregation. Canadian Journal of Soil Science, 84(4), 355-363. https://doi.org/10.4141/S04-003

Rillig, M. C., Wright, S. F., \& Eviner, V. T. (2002). The role of arbuscular mycorrhizal fungi and glomalin in soil aggregation : comparing effects of five plant species, 325333.

Rillig, M. C., Wright, S. F., Nichols, K. A., Schmidt, W. F., \& Torn, M. S. (2001). Large contribution of arbuscular mycorrhizal fungi to soil carbon pools in tropical forest soils. Plant and Soil, 233(2), 167-177. https://doi.org/10.1023/A:1010364221169

Ruiz Lozano, J. M., Azcón, R., \& Gomez, M. (1995). Effects of arbuscular-mycorrhizal Glomus species on drough tolerance: physiology and nutritional plant responses. Appl Environ Microbiol, 61(61 (2)), 456-460.

Saha, A. K., Saha, S., Sadle, J., Jiang, J., Ross, M. S., Price, R. M., ... Wendelberger, K. S. (2011). Sea level rise and South Florida coastal forests. Climatic Change, 107(1), 81-108. https://doi.org/10.1007/s10584-011-0082-0

Scholberg, J. M. S., \& Locascio, S. J. (1999). Growth response of snap bean and tomato as affected by salinity and irrigation method. HortScience, 34(2), 259-264.

Sherif, M. M., \& Singh, V. P. (1999). Effect of climate change on sea water intrusion in coastal aquifers. Hydrological Processes, 13(8), 1277-1287. https://doi.org/10.1002/(SICI)1099-1085(19990615)13:8<1277::AIDHYP765>3.0.CO;2-W 
Singh, A. (2018). Salinization of agricultural lands due to poor drainage: A viewpoint. Ecological Indicators, 95(March), 127-130. https://doi.org/10.1016/j.ecolind.2018.07.037

Smith, H. A., Freeman, J. H., Dittmar, P. J., \& Vallad, G. E. (2019). Vegetable Production Handbook of Florida 2018-2019.

Smith, S. E., \& Read, D. (2008). Mycorrhizas in agriculture, horticulture and forestry. In Mycorrhizal Symbiosis (pp. 611-XVIII). Elsevier. https://doi.org/https://doi.org/10.1016/B978-0-12-652840-4.X5000-1

Soussi, M., Santamaría, M., Ocaña, A., \& Lluch, C. (2001). Effects of salinity on protein and lipopolysaccharide pattern in a salt-tolerant strain of Mesorhizobium ciceri. Journal of Applied Microbiology, 90(3), 476-481. https://doi.org/10.1046/j.13652672.2001.01269.x

Steinkampf, W. . (1982). Origins and distribution of saline ground water in the Florida aquifer in coastal southwest Florida. U.S. GEOLOGICAL SURVEY Water-Resources Investigations 82-4052.

Talaat, N. B. (2015). Scientia Horticulturae Effective microorganisms modify protein and polyamine pools in common bean ( Phaseolus vulgaris L .) plants grown under saline conditions. Scientia Horticulturae, 190, 1-10.

https://doi.org/10.1016/j.scienta.2015.04.005

Toma, M. A., Soares de Carvalho, T., Azarias Guimarães, A., Martins da Costa, E., Savana da Silva, J., \& de Souza Moreira, F. M. (2017). Tripartite symbiosis of Sophora tomentosa, rhizobia and arbuscular mycorhizal fungi. Brazilian Journal of Microbiology, 48(4), 680-688. https://doi.org/10.1016/j.bjm.2017.03.007

U.S. Department of Agriculture. (2017). 500 Florida 2017 Census of Agriculture County Data. Retrieved fromhttps://www.nass.usda.gov/Publications/AgCensus/2017/Full_Report/Volume_ 1,_Chapter_2_County_Level/Florida/st12_2_0029_0029.pdf

Wang, S., Wu, Q. S., \& He, X. H. (2015). Exogenous easily extractable glomalin-related soil protein promotes soil aggregation, relevant soil enzyme activities and plant growth in trifoliate orange. Plant, Soil and Environment, 61(2), 66-71. https://doi.org/10.17221/833/2014-PSE

Wang, Shuguang, Feng, Z., Wang, X., \& Gong, W. (2011). Arbuscular mycorrhizal fungi alter the response of growth and nutrient uptake of snap bean (Phaseolus vulgaris L.) to O 3. Journal of Environmental Sciences, 23(6), 968-974. https://doi.org/10.1016/S1001-0742(10)60503-7

Wang, W., Zhong, Z., Wang, Q., Wang, H., Fu, Y., \& He, X. (2017). Glomalin contributed more to carbon, nutrients in deeper soils, and differently associated with climates and soil properties in vertical profiles. Scientific Reports, 7(1), 1-13. https://doi.org/10.1038/s41598-017-12731-7 
Werner, A. D., \& Simmons, C. T. (2009). Impact of sea-level rise on sea water intrusion in coastal aquifers. Ground Water, 47(2), 197-204. https://doi.org/10.1111/j.17456584.2008.00535.x

Whiffen, L. K., Midgley, D. J., \& McGee, P. A. (2007). Polyphenolic compounds interfere with quantification of protein in soil extracts using the Bradford method. Soil Biology and Biochemistry. https://doi.org/10.1016/j.soilbio.2006.08.012

Wright, S. F., \& Anderson, R. L. (2000). Aggregate stability and glomalin in alternative crop rotations for the central Great Plains. Biology and Fertility of Soils, 31(3-4), 249-253. https://doi.org/10.1007/s003740050653

Wright, S. F., Green, V. S., \& Cavigelli, M. A. (2007). Glomalin in aggregate size classes from three different farming systems. Soil and Tillage Research, 94(2), 546-549. https://doi.org/10.1016/j.still.2006.08.003

Wright, S. F., \& Upadhyaya, A. (1998). A survey of soils for aggregate stability and glomalin, a glycoprotein produced by hyphae of arbuscular mycorrhizal fungi. Plant and Soil, 198(1), 97-107. https://doi.org/10.1023/A:1004347701584

Wright, Sara F., Starr, J. L., \& Paltineanu, I. C. (1999). Changes in Aggregate Stability and Concentration of Glomalin during Tillage Management Transition. Soil Science Society of America Journal, 63(6). https://doi.org/10.2136/sssaj1999.6361825x

Wright, Sara F., \& Upadhyaya, A. (1996). Extraction of an abundant and unusual protein from soil and comparison with hyphal protein of arbuscular mycorrhizal fungi. Soil Science. https://doi.org/10.1097/00010694-199609000-00003

Zhou, M., Butterbach-Bahl, K., Vereecken, H., \& Brüggemann, N. (2017). A metaanalysis of soil salinization effects on nitrogen pools, cycles and fluxes in coastal ecosystems. Global Change Biology, 23(3), 1338-1352. https://doi.org/10.1111/gcb.13430 